\title{
Actuarial Fairness When Longevity Increases: An Evaluation of the Italian Pension System
}

\author{
Michele Belloni $^{\mathrm{a}}$ and Carlo Maccheroni ${ }^{\mathrm{b}}$ \\ a'Department of Economics, University Ca' Foscari of Venice, San Giobbe 873, Venice 30121, Italy. \\ E-mail: michele.belloni@unive.it \\ ${ }^{\mathrm{b}}$ Department of Statistics and Mathematics, University of Turin, Turin, Italy.
}

This study analyses the actuarial characteristics of the Italian pension system throughout its transition from defined benefit (DB) to notional defined contribution (NDC) rules, taking into account expected increasing longevity. Computations rely on ad hoc projected cohort mortality tables based on a limit survival scenario depicted by demographic experts. Most workers retiring in the coming years, whose pension is partly computed according to DB rules, will receive more-than-actuarially fair pensions. However, the generosity of the pension system has been significantly reduced for them by a recent reform that tightened early retirement eligibility requirements. Disability benefits remain (extremely) generous when claimed before age (57) 60. Steady-state NDC pensions, due to dynamic efficiency, are less than actuarially fair. They further deviate from actuarial fairness due to the specific rules, based on historical mortality, adopted by the Italian law for computing and updating benefits while facing increasing longevity. Cohort mortality projections should be used to handle longevity changes in NDC schemes.

The Geneva Papers (2013) 38, 638-674. doi:10.1057/gpp.2013.27

Keywords: social security; notional defined contribution; actuarial fairness; longevity; cohort mortality forecasts

Article submitted 03 January 2013; accepted 22 July 2013; published online October 2013

\section{Introduction}

In the last two decades, population ageing and low economic growth have undermined the financial stability of several pay-as-you-go defined benefit (DB) pension schemes. Some countries (including Italy, Latvia, Poland and Sweden) have reacted to the crises by retaining their pay-as-you-go financing method, but replacing their DB with a notional defined contribution (NDC) pension system. An NDC scheme consists of an individual account system to which contributions are earmarked and interests notionally paid; at retirement, the notionally accumulated sum is converted into the pension taking into account life expectancy, that is, incorporating actuarial fairness.

An ideal actuarially fair pension scheme is characterised by both actuarial fairness and actuarial fairness at margin. Actuarial fairness guarantees that, for each individual, the discounted sum of contributions paid during the working career is equal to the discounted sum of expected benefits received during retirement. Actuarial fairness at margin ensures 
that, for each individual, any supplementary contributions to be paid in case of postponed retirement will correspond to additional pension benefits. ${ }^{1,2}$

An NDC scheme cannot guarantee the two above described ideal actuarial conditions; however, it should satisfy the weaker conditions of quasi-actuarial fairness, and quasiactuarial fairness at margin. ${ }^{3}$ These conditions recognise that, in a dynamic efficient economy, only a funded DC pension scheme can guarantee pure actuarial fairness. ${ }^{4}$ Since an NDC system is pay-as-you-go financed, its equilibrium rate of return is given by the wage bill growth rate. ${ }^{5}$ Moreover, an NDC scheme should broadly allow for differences in life expectancy across different population groups within a cohort. ${ }^{6}$

According to official European demographic projections, life expectancy at age 65 for the EU-27 countries is expected to increase by about five years by $2060 .^{7}$ Implementations of quasi-actuarially fair NDC systems need to guarantee that life expectancy used to compute the annuity at retirement is as close as possible to actual, ex post, residual life. ${ }^{6}$ Palmer $^{8}$ has suggested three procedures to handle increasing longevity in NDC schemes. ${ }^{9}$ The first procedure consists in forming a committee of demographic experts in charge of the analysis of long-run scenarios and the publication of official cohort projections. Revisions are gradual, and only occur when changes in long-run trends are documented. They always apply to non-retired cohorts and are increasingly small as cohorts approach retirement. The second procedure consists in estimating cohort life tables based on historical cross-sectional data. In this case, periodical adjustments are necessary to avoid producing systematically more-than-actuarially fair annuities. The third procedure envisages the use of recent crosssectional survival data to compute annuities at retirement and to regularly adjust the pensions of all retirees on the basis of more updated data.

In 1995, the Italian pension system was reformed and an NDC scheme was introduced to replace the previous unsustainable DB scheme. The 1995 reform (known as the "Dini" reform) set up a transitional phase towards the new rules lasting almost 30 years. Transition rules were partly modified by a subsequent reform in 2011 ("Monti-Fornero" reform). In the coming two decades, pensions will be partly computed according to the old rules; consequently, their actuarial features will still depend on the characteristics of the former DB scheme. Moreover, (N)DC pension benefits are computed on the basis of updated cross-sectional mortality tables, while benefits of retired individuals are unaffected by longevity changes occurring during retirement. A comparison between

\footnotetext{
${ }^{1}$ Legros (2006).

${ }^{2}$ A formal definition of these actuarial concepts is provided in the section "Actuarial indicators". In the literature, actuarial fairness is often named actuarial fairness "on average", to stress that in contrast to the notion of actuarial fairness at margin, it takes into account the whole career profile of the agent, without focusing on the last years of work (Legros, 2006, p. 211) In this paper, we use the term actuarial fairness as synonymous for actuarial fairness on average.

${ }^{3}$ Holzmann (2006).

${ }^{4}$ See, e.g. Lindbeck (2006); Holzmann (2006).

${ }^{5}$ See Samuelson (1958); Aaron (1966).

${ }^{6}$ Disney (2004).

${ }^{7}$ EPC-WGA (2011).

${ }^{8}$ Palmer (2006).

${ }^{9}$ See also Bengtsson and Keilman (2003).
} 
640

these pension rules and the above suggested procedures indicates that the Italian NDC pension system may violate actuarial principles if longevity continues to rise.

Similar issues are likely to arise for other countries that have introduced NDC pension systems, such as Poland, which adopts alike pension rules to counteract longevity improvements. ${ }^{10}$ Sweden has also adopted a similar approach; nevertheless, this country has introduced an automatic long-run correction mechanism (called pension-debt adjustment mechanism) which indexes downward notional capital of workers and benefits if actual and expected longevity differ. ${ }^{11}$ Benefits of Latvians are instead calculated from projected cohort mortality tables prepared by demographic experts. ${ }^{12}$

Various studies analysed the actuarial characteristics of the Italian pension system after the 1995 reform. Ferraresi and Fornero ${ }^{13}$ and Fornero and Castellino ${ }^{14}$ rely on a representative agent approach and show that the former DB scheme was extremely generous, whereas the future NDC will be almost actuarially fair. These findings have been largely confirmed by microsimulation models. ${ }^{15}$ Marano et al. ${ }^{16}$ point out that the NDC formula departs from actuarial fairness if one accounts for the interaction between old-age and social assistance provisions. Other studies quantify the extent of within-cohort redistribution of the Italian NDC pension system induced by differential mortality by gender, education, income ${ }^{17}$ and regions. ${ }^{18}$ Most of the cited studies assume static mortality; none of them incorporate cohort mortality tables. To our knowledge, the effects of the 2011 reform on the actuarial characteristics of the Italian pension system have not been analysed yet.

The contribution of this paper is twofold. First, extending Ferraresi and Fornero ${ }^{13}$ and Fornero and Castellino, ${ }^{14}$ we analyse the actuarial features of the Italian pension system accounting for dynamic mortality. We compare the Italian pension rules with the first procedure suggested by Palmer $^{8}$ to counteract increasing longevity in NDC schemes. In addition, we evaluate the impact of the 2011 pension reform on the actuarial characteristics of the Italian pension system. To these aims, we build ad hoc projected cohort- and genderspecific mortality tables based on a limit survival scenario depicted by demographic experts.

The paper proceeds as follows. The next section illustrates the institutional framework, the subsequent section describes the projected life tables. The latter sections describe the model and the actuarial indicators. The sixth section shows the main results, the penultimate section provides a sensitivity analysis with respect to some key model assumptions and the final section concludes. Three appendices describe pension projections, detailed results and mortality forecasts methodology.

${ }^{10}$ See Chlon et al. (1999).

${ }^{11}$ Palmer (2000).

${ }^{12}$ Palmer et al. (2006).

${ }^{13}$ Ferraresi and Fornero (2000).

${ }^{14}$ Fornero and Castellino (2001).

15 See Borella and Coda Moscarola (2006); Marano et al. (2012).

${ }^{16}$ Marano et al. (2012).

${ }^{17}$ Mazzaferro et al. (2012).

${ }^{18}$ Caselli et al. (2003). 


\section{Institutional framework}

To improve the social security budget, an impressive sequence of reforms was introduced in Italy during the $1990 \mathrm{~s}$ and the $2000 \mathrm{~s} .{ }^{19}$ Most of these changes were designed to be effective in the short run by acting on specific parameters of the existing system, such as the minimum retirement age. Law No. 335/1995, which was designed instead to improve the budget in the long run, replaced the existing DB scheme with an NDC one.

In line with its long-run view, the 1995 law classified workers into three groups: the oldest, the middle-aged and the youngest. The oldest are those workers who, at the time of the reform, had accrued more than 18 years of seniority. They were unaffected by the reform. The middle-aged are those who had accrued less than 18 years of seniority by the end of 1995. Their pension is computed according to a mixed (pro-rata, PR henceforth) system where old and new rules are combined in proportion to the number of years worked up to and after 1995. The youngest, to whom the new system fully applies, are those who started working after 1995. Recently, Law No. 214/2011 extended the PR system to the oldest. The pension of this group of workers is thus computed according to a mixed system (extended pro-rata, DB-PR henceforth) where old and new rules are combined considering the number of years worked up to and after 2011.

About two-thirds of the workforce is insured with the Istituto Nazionale della Previdenza sociale (INPS), the main social security institution in Italy. The Fondo Pensioni Lavoratori Dipendenti (FPLD) is the largest INPS pension scheme, enrolling almost all employees in the private sector. Separate schemes with different pension rules exist for the self-employed, civil servants and other categories of workers. The development of voluntary-based second and third pillars has been recently encouraged; both participation and contributions remain however modest. ${ }^{20}$ Considering the complexity of the framework generated by the reforms, in this study we focus on the FPLD fund.

Male (female) workers can claim an old-age pension at age 66 (62, progressively increasing to 66 by 2018) once 20 years of seniority have been accrued. By 2021, in compliance with a recent EU Commission recommendation, the minimum retirement age for the old-age pension will be raised to 67 . Early retirement has been severely restricted by the 2011 reform; it can be claimed by males (females) who accumulate 42 (41) years and one month of seniority. ${ }^{21}$

The DB benefit is computed as the product of three factors: pensionable earnings, seniority and annual return. Pensionable earnings are the average wage of the last years of work. The number of years to include in the computation of pensionable earnings was progressively increased from 5 to 10 by the reforms of the 1990s. Seniority includes the number of years of regular contribution to the scheme, as well as years of notional contribution spent during outof-work periods (e.g. unemployment spells, maternity leaves and military service). Total seniority is topped at 40 years. Annual return is a decreasing function of pensionable earnings, equal to 2 per cent for a large part of the earnings distribution. Payroll taxes grew from 19 per cent in 1967 (the first relevant year for our simulation) to 33 per cent

\footnotetext{
${ }^{19}$ Pension expenditure grew from 7.4 per cent of GDP in 1970 to 14.9 per cent in 1992 (Brugiavini and Galasso, 2004).

${ }^{20}$ According to COVIP (2011), 24.1 per cent of workers have adhered to supplementary pension funds and assets are 4.6 per cent of GDP.

${ }^{21}$ Eligibility conditions are linked to life expectancy.
} 
642

( 9.19 per cent, that is, about 28 per cent of the total, are paid by the employee). Pensions are price-indexed. $^{22}$

The DC old-age/early retirement pension for a worker retiring at age $x$ is computed as:

$$
P(x)^{D C-O L D}=\left[\alpha_{a} w_{a}+\sum_{i=1}^{a-1} \alpha_{i} w_{i} \prod_{j=i}^{a-1}\left(1+\bar{g}_{j}\right)\right] \delta_{x},
$$

where $\alpha_{i}$ and $w_{i}$ are payroll tax rate and wages when seniority is $i, a$ is seniority at retirement and $\bar{g}_{j}$ is the geometric mean of nominal GDP growth rate in the 5 years preceding the year in which seniority is $j$. The amount in square brackets is the nominally accrued fund at retirement. $\delta_{x}$ is the conversion coefficient for retirement at age $x$, defined as:

$$
\begin{gathered}
\delta_{x}=\left(\frac{\sum_{s=m, f} d i r_{x, s}+i n d_{x, s}}{2}-k\right)^{-1} \\
d i r_{x, s}=\sum_{t=0}^{\Omega-x} \frac{\ell_{x+t, s}}{\ell_{x, s}}\left(1+g_{f}\right)^{-t} \\
\text { ind }_{x, s}=\theta_{s} \sum_{t=0}^{\Omega-x} \frac{\ell_{x+t, s}}{\ell_{x, s}}\left(1-\frac{\ell_{x+t+1, s}}{\ell_{x+t, s}}\right)\left(1+g_{f}\right)^{-t} \Theta_{x+t, s} a_{x+t+1}^{W}, \\
a_{x+t+1}^{W}=\sum_{\tau=1}^{\Omega-x-t+\varepsilon_{s}} \frac{\ell_{x+t+\tau-\varepsilon_{s},-s}}{\ell_{x+t+1-\varepsilon_{s},-s}}\left(1-q_{x+t+\tau-\varepsilon_{s},-s}^{v e d}\right)\left(1+g_{f}\right)^{-\tau},
\end{gathered}
$$

where $\ell_{x+t, s} / \ell_{x, s}$ is the gender-s-specific conditional survival probability from age $x$ to age $x+t ; \Omega$ is the maximum life span, $g_{f}$ is the long-run expected GDP growth rate; $\theta_{s}$ is the fraction of the annuity paid to the widow(er) $\left(\theta_{s}=\theta \times c^{e t}\right.$, where $\theta=0.6$ and $c^{e t}$ is a earningrelated reduction factor, set equal to (0.7) 0.9 if $s$ is (fe)male); $\Theta$ is the age-and-genderspecific probability to be married. ${ }^{23} a_{x+t+1}^{w}$ is the expected present value of a unitary annuity paid to the widow(er) at time ${ }_{x+t+1} ; \varepsilon$ is the age difference between pensioner and his/her widow(er) $\left(\varepsilon_{s}=+3(-3)\right.$ if $\left.s=m(f)\right) ;-s$ is the gender of the widow(er); $q^{\text {ved }}$ is the age-andgender-specific probability for the widow(er) to remarry. ${ }^{24} k$ is an actuarial adjustment factor that takes into account the number of pension payments made to the retiree each year. ${ }^{25}$ Differences in death probabilities between genders are averaged out (see Eq. 2). The retirement age $x$ is flexible between 62 and 70 (before the 2011 reform: between age 57 and 65). According to the current legislation, conversion coefficients have to be revised every three years, to incorporate updated mortality tables and new GDP growth rates projections; before 2007 the temporal validity of the coefficients was equal to 10 years.

\footnotetext{
${ }^{22}$ A formal description of the DB and PR pension formulas is provided by Fornero and Castellino (2001).

${ }^{23}$ ISTAT (2007).

${ }^{24}$ ISTAT (2006).

${ }^{25}$ Formally, $k=0.5-(6 / 13 n)$, where $n$ is the number of (anticipated) pension payments made to the retiree each year. Currently, $k=0.4615$ since $n=12$ (NVSP, 2006).
} 
Disability and survivor pensions are also financed through social security contributions. Disability benefits (pensione di inabilità) are paid to claimants who, after medical screening, result to be in the permanent and total impossibility of doing any kind of work activity (Law No. 222/1984). Additional requirements to claim this benefit are five years of enrolment to INPS and at least three years of contributions in the previous five. The disability benefit is computed first applying either DB (prior to the 2011 reform)/DB-PR, PR or DC rules, as established for the old-age/early retirement pension. To the benefit computed in this way, a "contributory bonus"- equal to the years of contributions from the age of claiming to the age of 60 -is then added. If the claimant is younger than 57 , the favourable conversion coefficient for retirement at age 57 is applied.

The DC disability pension claimed at age $x$ is given $b^{26}$ :

$$
\begin{aligned}
P(x)^{D C-D I S}= & \left\{\left[\alpha_{a} w_{a}+\sum_{i=1}^{a-1} \alpha_{i} w_{i} \prod_{j=i}^{a-1}\left(1+\bar{g}_{j}\right)\right]\right. \\
& \left.+\left[\frac{\sum_{i=1}^{5} w_{a-i}^{*}}{5} 0.33(60-x)\right]\right\} \delta_{\max [x, 57]},
\end{aligned}
$$

where the amount in the first set of square brackets is the nominally accrued fund when the person becomes disabled (see Eq. 1), and $w_{i}^{*}$ is the (appropriately adjusted) wages in the preceding 5 years). The amount in the second set of square brackets is the "contributory bonus".

Survivor benefits are paid to the worker's (pensione indiretta) or old-age, early retirement and disability beneficiary's (pensione di reversibilità) relatives, including the widow(er), minor or disabled children, children in full-time education or, in particular cases, even parents or brothers and sisters. The payment amount of survivor benefits depends on the number of recipients and on their earnings. The deceased worker needs to meet the minimum contribution requirements established for the disability pension; see above.

\section{Projected cohort mortality tables}

A sizeable downward trend in old-age mortality has taken place in Italy since the 1970s. In the last 40 years, life expectancy at age $60\left(e_{60}\right)$ gained nearly six years. ${ }^{27}$ Currently, $e_{60}$ is about 22 years for males and 26 years for females. The greatest improvements for the future are expected for the oldest old, that is, individuals aged 80 and over. In a context characterised by further progress in the prevention and cure of diseases and by firmly-rooted life styles able to promote "successful ageing", younger cohorts are expected to live longer than older ones. ${ }^{28}$

The future mortality evolution will be influenced by tendencies that emerge in the last phase of life. Two theories contrast on this point. According to the theory of "compression of

\footnotetext{
${ }^{26}$ Throughout the paper, the symbol $x$ defines the age at which the individual leaves the labour force, regardless of the specific exit route which he or she may use (i.e. either old-age/early retirement or disability pension).

27 Caselli et al. (2003); ISTAT (2010).

${ }^{28}$ Christensen et al. (2009).
} 
mortality," 29 life expectancy cannot exceed the limit of 85 years and, as many more people gain years of life, there will be a process of concentration of their deaths in a narrow interval astride this threshold. The theory of "expansion of mortality" 30 on the contrary, points out that the recorded maximum life span will continue to increase. ${ }^{31}$ This last theory is backed up by statistics regarding the maximum life span gradually reached by persons who have died in the last 30 years in developed countries, and by the observed decline in mortality of the oldest old (i.e. aged 80 years and more).

In this study, we develop a deterministic forecast for the Italian cohorts 1945-2000 which relies on the theory of expansion of mortality. In this framework, characterised by a limit scenario where the whole survival curve is shifted towards higher ages, life expectancy will continue to rise in the future. ${ }^{32}$ To build limit life tables - that is, the life tables of the selected limit scenario ${ }^{33}$ - set in the distant future, we follow the indications provided by recent interdisciplinary studies which have depicted the most important traits for human survival. ${ }^{34}$ Cohort forecasts are obtained by computing period age-specific death probabilities on the forecast time frame: we connect period tables with limit life table; in the first years of the projections, our tables reflect the characteristics of current mortality, while for farther projection years, they progressively come closer to those of the limit scenario.

Projected cohort mortality tables typically cover a very long period of time (e.g. our limit life tables are set around year 2150). A scenario approach like the one we adopt is particularly suitable to account for such a long-run time frame. Alternative approachesincluding the stochastic Lee and Carter $^{35}$ model-are instead often preferred for short- and mid-time projections. ${ }^{36,37}$ In our exercise, we corroborate the actuarial findings based on our projected life tables with alternative results based on the long-run probabilistic mortality projections for Italy recently implemented by the United Nations. ${ }^{38,39}$ By exploiting alternative percentiles of the UN probabilistic forecasts, we also account for the impact of projection uncertainty on the actuarial indicators.

Table 1 compares the estimated life expectancy at birth $\left(e_{0}\right)$ and at age $65\left(e_{65}\right)$ with the corresponding statistics provided by the most recent official projections. ${ }^{40,41}$ The table

${ }^{29}$ See, e.g. Fries $(1983,1989)$.

${ }^{30}$ Myers and Manton (1984); Olshanski et al. (1993); Robine and Cheung (2008).

31 See Wilmoth and Lundstrom (1996); Wilmoth (2000).

32 Kannisto (1996).

33 Tabeau et al. (2002); Booth and Tickle (2008).

${ }^{34}$ See Robine et al. (2006).

${ }^{35}$ Lee and Carter (1992).

${ }^{36} \mathrm{Li}$ and Gerland (2012).

${ }^{37}$ Lee and Carter (1992) assume that the sensitivity of the logarithm of the age-specific mortality rate to the time trend is constant over time (See p. 660 in Lee and Carter, 1992). This is a strong assumption in very long-term forecasts.

${ }^{38}$ Raftery et al. (2012).

39 The UN mortality projections represent part of the probabilistic population projections for all countries. They are carried out in two steps. In the first step, probabilistic projections of life expectancy at birth are based on a Bayesian hierarchical model (Raftery et al., 2013). In the second step, these life expectancies are converted into age-specific mortality rates using extended model life tables (Li and Gerland, 2012). See UN (2012) for details. The UN mortality projections stretch up to 2100 and thus allow to reconstruct mortality tables for cohorts 1945 1980. Cohorts born after 1980 are not extinct in 2100 .

${ }^{40}$ ISTAT (2008). 
Table 1 Predicted period life expectancy at birth $\left(e_{0}\right)$ and at age $65\left(e_{65}\right)$ : our tables vs official tables

\begin{tabular}{|c|c|c|c|c|c|c|c|c|}
\hline \multirow[t]{3}{*}{ Forecast/Year } & \multicolumn{4}{|c|}{ Males } & \multicolumn{4}{|c|}{ Females } \\
\hline & \multicolumn{2}{|c|}{2030} & \multicolumn{2}{|c|}{2050} & \multicolumn{2}{|c|}{2030} & \multicolumn{2}{|c|}{2050} \\
\hline & $e_{0}$ & $e_{65}$ & $e_{O}$ & $e_{65}$ & $e_{0}$ & $e_{65}$ & $e_{O}$ & $e_{65}$ \\
\hline Our tables & 83.0 & 20.8 & 86.6 & 23.4 & 88.2 & 25.0 & 91.5 & 27.8 \\
\hline ISTAT (2008) — high & 84.0 & 21.9 & 86.8 & 24.1 & 89.1 & 25.8 & 91.6 & 27.9 \\
\hline ISTAT (2008) -main & 82.2 & 20.5 & 84.5 & 22.2 & 87.5 & 24.4 & 89.5 & 26.0 \\
\hline ISTAT (2008) -low & 80.2 & 19.0 & 81.9 & 20.2 & 85.7 & 22.9 & 87.2 & 24.1 \\
\hline
\end{tabular}

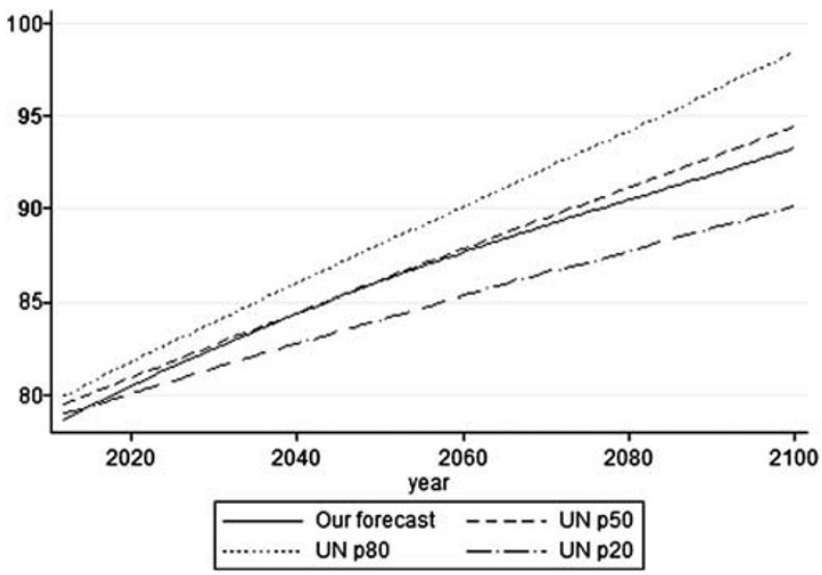

Figure 1. Predicted period life expectancy at birth: our tables vs United Nations tables—percentiles 20, 50 and 80.

indicates that our forecasts lie between ISTAT-main and ISTAT-high mortality scenarios. Figure 1 contrasts our estimated $e_{0}$ with corresponding values from the UN projectionspercentiles 20, 50 and 80 ; it highlights that our projections are very close to those obtained by the United Nations, median values. Finally, Figure 2 shows our forecasted survival curves by cohort for males; a similar figure can be drawn for females. The figure highlights two typical characteristics of the mortality process of younger cohorts: the "rectangularisation" of life tables, that is, deaths are concentrated around a narrower interval of age, and the increase in life span. As a consequence of these improvements, males $e_{60}$ is expected to increase from 23.1 years (cohort 1945) to 27.1 years (cohort 1970), up to a striking 31.4 years (cohort 2000). ${ }^{42}$

${ }^{41}$ At an intermediate step, our approach forecasts periodic life tables, which can be compared with those obtained by official forecasts. It should be pointed out, however, that the methodological approaches used in a very longterm forecast and in standard demographic forecasts (which usually cover a period of 30-50 years) are extremely different. Therefore, a formal comparison between the two tables cannot be conducted.

${ }^{42}$ No official cohort mortality tables for the overall population exist in Italy. There exist two cohort tables (called RG48 and IP55, pertaining to the 1948 and 1955 cohorts) used by Italian insurance companies to compute 


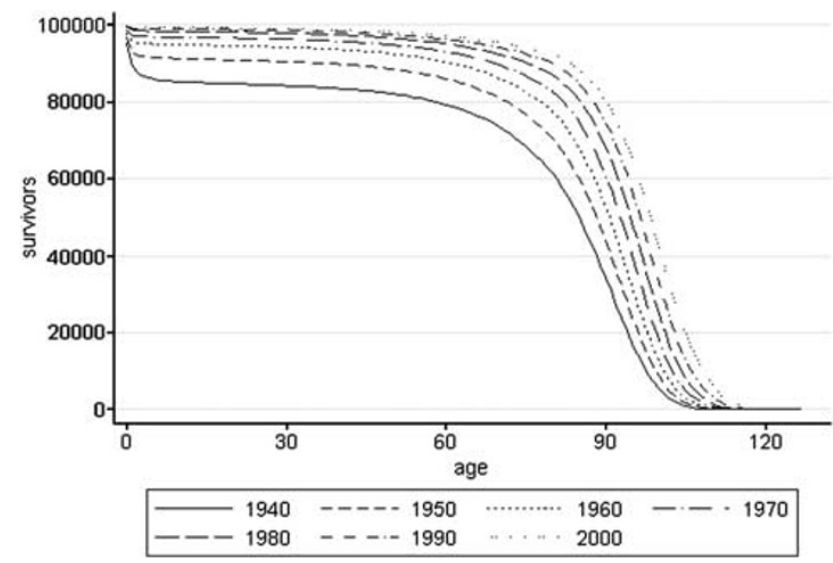

Figure 2. Projected survival curves by cohort: males.

\section{Representative agents}

We consider a set of representative agents subjects to either DB/DB-PR, PR or (N)DC pension rules. Each analysed individual represents a typical employee born in a given year, of a given gender and occupation (blue or white-collar). Agents are characterised by a stylised working career, described by an age at enrolment, a lifetime wage profile and a set of alternative retirement ages. The main features of the working career (e.g. age of entry into the labour market) are kept constant across cohorts to better highlight the impact of both normative and mortality changes on the actuarial indicators.

Based on empirical evidence obtained from the Bank of Italy's survey of household's income and wealth (SHIW), we assume that white-collar workers enrol into the pension scheme at age 24, while blue-collar workers enrol at age 22 if female, or at age 20 if males. We further assume that, once enrolled, agents keep contributing to the same scheme until retirement. ${ }^{43}$ Given our assumptions, agents become eligible to claim old-age or early retirement benefits between the ages of 62 and 67; specific eligibility varies with gender, occupation and year of birth. ${ }^{44}$

premiums. They refer to the annuitant population and correct for self-selection. Owing to self-selection of healthier individuals, the annuitants' life expectancy is longer than the whole population's.

${ }^{43}$ Using the SHIW data (various cross-sections) we compute the average age of entry into the labour market by gender and occupation. To avoid overestimation of accrued seniority at retirement, we account for an average period of 3 years spent out of the labour market and not compensated by notional contributions (see the section "Institutional framework"). This figure has been computed by Belloni and Alessie (2009), exploiting INPS micro data.

44 Specifically, male blue-collar workers are eligible at age 62, female blue-collar workers at age 63 (cohorts 1950-1951 at age 62), female white-collar workers at age 65 (cohorts 1950-1951 at age 62, cohort 1952 at age 63 ), male white-collar workers at age 66. We additionally consider "late" male white-collar workers, who enroll at age 28. Differently from the other stylised workers, these agents become eligible for the old-age benefits (at age 67, or at age 66 if born in 1950-1954) with less than 40 years of accrued seniority. We will show that the 


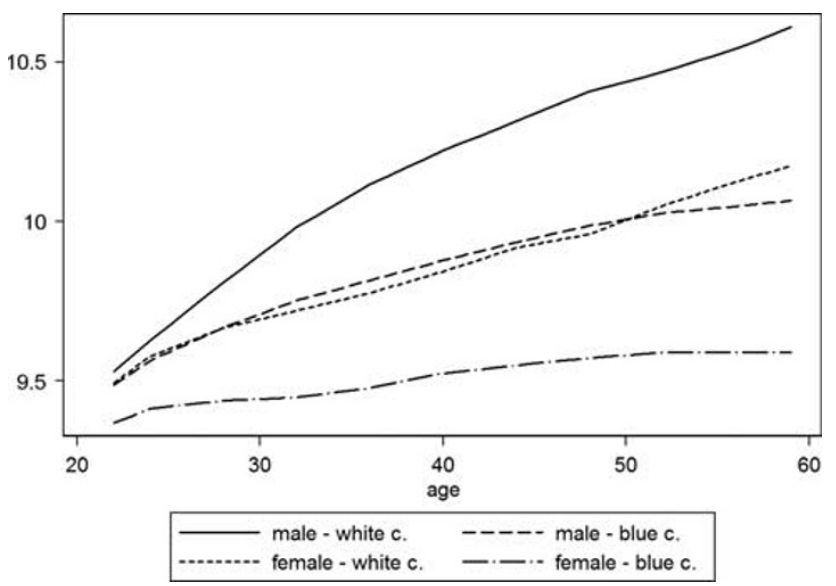

Figure 3. Estimated age-wage profiles by gender and occupation. Note: log-wages (2009 euros); cohort 1950.

Lifetime wage profiles are obtained as predictions from a random effects model for individual wages estimated on the Italian administrative data Estratti Conto INPS, a panel data set that covers the period 1985-1997 and includes 1/365 of the Italian private sector workforce. In the wage model, the log of wages is regressed against an age spline, a variable capturing the cohort effect, a set of year, sector and area of work dummies. The model is estimated separately by gender and occupation (blue- and white-collar workers). Figure 3 displays the estimated lifetime wage profiles: among the four groups, male white-collar workers have the steepest and highest profile while female blue-collar workers have the less dynamic careers and are the poorest. Owing to self-selection problems, the estimation samples only include individuals younger than age 60; above age 59, we assume that wages grow with age at a rate equal to the growth rate estimated at ages 55-59. ${ }^{45}$

Given these stylised careers, each representative agent is assigned to a specific pension regime. Table 2, for example, reports assigned pension regime and retirement years by cohort for male white-collar workers. It shows that agents born between 1945 and 1953 are subject to the DB-PR rules, since in 1995 they had accumulated 18 years of contributions or more. Depending on retirement age (given our assumptions, male white-collar workers acquire eligibility at age 66) and cohort, these agents claim pension benefits between year 2012 and 2023. Agents born between 1954 and 1970 are subject to the PR rules and retire between 2020 and 2040. Finally, agents born in 1971 or later are subject to the DC rules and

effect of the pro rata extension on the actuarial indicators depends on whether the individual has reached the threshold of 40 years of seniority at retirement (see the section "Institutional framework").

${ }^{45}$ Following Heckman and Robb (1985) and Kapteyn et al. (2005), we assume that wages differ across cohorts due to the macroeconomic conditions when individuals enter into the labour market. These conditions are summarised by productivity growth and are approximated by GDP per capita. This means that the age-wage profiles illustrated in Figure 3 shift upward (or downward) by cohort, incorporating historical and projected GDP growth. Including cohort effects in the wage model allows for a consistent estimate of the age-wage profiles. Additional details are provided upon request. 
Table 2 Pension regime and retirement years by cohort: male white-collar workers

\begin{tabular}{cccccccc}
\hline Cohort & Start & Sen.1995 & Regime & & \multicolumn{3}{c}{ Retirement years } \\
\cline { 1 - 3 } \cline { 6 - 7 } \cline { 5 - 7 } & & & & Age 66 & $\ldots$ & Age 70 \\
\hline 1945 & 1969 & 26 & DB-PR & & - & & 2015 \\
$\ldots$ & $\ldots$ & $\ldots$ & $\ldots$ & & $\ldots$ & & $\ldots$ \\
1953 & 1977 & 18 & DB-PR & & 2019 & & 2023 \\
1954 & 1978 & 17 & PR & & 2020 & & 2024 \\
$\ldots$ & $\ldots$ & $\ldots$ & $\ldots$ & & $\ldots$ & & $\ldots$ \\
1970 & 1994 & 1 & PR & & 2036 & & 2040 \\
1971 & 1995 & 0 & DC & & 2037 & & 2041 \\
$\ldots$ & $\ldots$ & $\ldots$ & $\ldots$ & & $\ldots$ & & $\ldots$ \\
2000 & 2024 & 0 & DC & & 2066 & & 2070 \\
\hline
\end{tabular}

Notes: Start=enrolment year; sen.1995=seniority accrued at the end of 1995; regime: DB-PR=extended pro rata, $\mathrm{PR}=$ pro rata, $\mathrm{DC}=$ notional defined contribution.

retire in 2037 or later. Agents can claim disability benefits at younger ages if qualified (see the section "Institutional framework"). A similar categorisation of workers is obtained for the other types of agents.

Historical and projected values of key macroeconomic indicators such as GDP growth rates, inflation rates and long-run (10 years' maturity) government bond interest rate are used in the computation of pension benefits and corresponding actuarial indicators (see the next section). In our main macroeconomic setting, the projected long-run real GDP growth rate ( $g_{f}$, see the section "Institutional framework") is equal to 1.5 per cent and the long-run riskless interest rate ( $r$, see the next section) is equal to 2 per cent. ${ }^{46}$ The implied spread $\left(r-g_{f}=0.5\right.$ percentage points) is coherent with a dynamic efficient economy, although it envisages a limited dominance of the financial market with respect to the pay-as-you-go system. In a sensitivity analysis we consider alternative macroeconomic settings where the spread between these two macroeconomic variables is wider.

Finally, in our simulations we consider three alternative normative scenarios: baseline 2011 $\left(B_{2011}\right)$, baseline $1995\left(B_{1995}\right)$ and quasi-actuarial benchmark $(A B)$. The first two incorporate actual pension rules. Scenario $B_{2011}$ considers current pension rules, while scenario $B_{1995}$ accounts for pension rules existing right after the 1995 reform. Differently from the former, the latter scenario: (i) considers DB (instead of DB-PR) pension rules and (ii) assumes a temporal validity of conversion coefficients equal to 10 (instead of 3 ) years (see the section "Institutional framework"). To compute conversion coefficients in scenarios $B_{2011}$ and $B_{1995}$, we exploit the cross-sectional versions of our projected cohort mortality tables. The $A B$ scenario considers hypothetical cohort- and gender-specific conversion coefficients, formally defined as

$$
\delta_{x, s}^{c o}=\left(d i r_{x, s}^{c o}+i n d_{x, s}^{c o}\right)^{-1}
$$

where $d i r_{x, s}^{c o}$ and $i n d_{x, s}^{c o}$ are defined in Eqs (3-4) and computed using cohort-co mortality rates. 


\section{Actuarial indicators}

We compute two actuarial indicators: the present value ratio (PVR) and the implicit tax/ subsidy rate (TAX). The former is used to evaluate actuarial fairness while the latter measures actuarial fairness at margin. Both of them require the computation of social security wealth (SSW). The SSW for retirement at age $x$, computed at the beginning of the working career, is given by:

$$
\operatorname{SSW}(x)=-P V C(x)+P V B(x)+P V W(x),
$$

where the three components represent the actuarial present value of: contributions $(P V C)$, retirement and disability benefits including survivor benefits $(P V B)$, and survivor benefits paid before retirement to the deceased worker's widow(er) $(P V W)$. They are defined as:

$$
\begin{gathered}
P V C(x)=\sum_{j=1}^{a} \alpha_{j} \hat{w}_{j}^{*} \frac{\ell_{e+j-1, s}^{c}}{\ell_{e, s}^{c}}(1+r)^{-j+1}, \\
P V B(x)=P(x) \sum_{j=a+1}^{\Omega-e} \frac{\ell_{e+j-1, s}^{c}}{\ell_{e, s}^{c}}(1+r)^{-j+1} \\
\times\left[1+\theta_{s}\left(1-\frac{\ell_{e+j, s}^{c}}{\ell_{e+j-1, s}^{c}}\right)(1+r)^{-1} \Theta_{e+j-1, s} a_{e+j}^{W}\right], \\
P V W(x)=\theta_{s} \sum_{j=5}^{a} P(e+j-1)_{S C}^{R E-O L D} \frac{\ell_{e+j-1, s}^{c}}{\ell_{e, s}^{c}} \\
\times\left(1-\frac{\ell_{e+j, s}^{c}}{\ell_{e+j-1, s}^{c}}\right)(1+r)^{-j} \Theta_{e+j-1, s} a_{e+j}^{W},
\end{gathered}
$$

where $\alpha_{j}$ and $\hat{w}_{j}^{*}$ are respectively payroll tax rate (see the section "Institutional framework") and wages (at constant prices as predicted by the wage model; see the previous section) when accrued seniority is $j, e$ is the age at which the employee starts contributing to the scheme, $a$ is the number of years of seniority accrued at retirement or when claiming a disability pension, $c$ is the cohort, $r$ is the riskless interest rate, ${ }^{47}$ while the other symbols are defined in the section "Institutional framework". $P(x)$ is defined as follows:

$$
P(x)=\gamma_{x} P(x)_{S C}^{R E-O L D}+\left(1-\gamma_{x}\right) P(x)_{S C}^{R E-D I S}
$$

where $R E$ is the pension regime (either $\mathrm{DB} / \mathrm{DB}-\mathrm{PR}, \mathrm{PR}$ or $\mathrm{DC}$, depending on cohort and type of agent), $S C$ is the normative scenario $\left(B_{2011}, B_{1995}\right.$ or $\left.A B\right), O L D$ and $D I S$ are old-age/early retirement and disability formula respectively, while $\gamma_{x}=1$ if the individual at age $x$ is eligible

${ }^{47}$ We approximate $r$ with the long-run (10 years' maturity) government bond interest rate. See Queisser and Whitehouse (2006) for a discussion of the appropriate discount rate. 
650

for old-age/early retirement and 0 otherwise. ${ }^{48}$ Under the assumption of continuous working careers, $x=e+a$. As mentioned in the section "Institutional framework", the legislation on survivor benefits envisages a variety of possible beneficiaries and pension amounts. In Eqs (10-11) for simplicity we assume that, among the relatives of the deceased worker/ retiree, survivor benefits are only paid to the widow(er); this is in line with what is established by law in the computation of the conversion coefficients (see Eq. 2). Financial flows are annual and anticipated.

The PVR for retirement at age $x$, computed at the beginning of the working career, is given by:

$$
P V R(x)=\frac{P V B(x)+P V W(x)}{P V C(x)}
$$

showing how much the system returns to the worker for each euro paid. A pension system is defined to be actuarially fair if $P V R(x)=1$ (i.e. $S S W(x)=0$ in Eq. 8). A pension system is defined to be quasi-actuarially fair if $\operatorname{PVR}(x)=1$ when $r=g_{f}$.

The TAX for retirement at age $x$, computed at the beginning of the working career, is given by:

$$
\operatorname{TAX}(x)=\frac{-A C C(x)}{\hat{w}_{a+1}^{*}\left(\ell_{e+a, s}^{c}\right)(1+r)^{-a} / \ell_{e, s}^{c}},
$$

where $\hat{w}_{a+1}^{*}$ is the expected wage for the following year in case of postponed retirement, as predicted by the wage model described in the previous section, while the numerator is called accrual and is defined as:

$$
A C C(x)=\operatorname{SSW}(x+1)-\operatorname{SSW}(x) .
$$

If retirement is postponed by one year, the SSW varies due to two reasons. First, it decreases because of additional contributions to pay. Second, it varies due to the difference in the present values of pension benefits associated with the alternative retirement options. The sign of this difference is undefined because a shorter retirement period is generally associated with a higher pension benefit. In Eq. (14), the accrual is normalised with respect to the expected wage for the additional year of work. A pension system is defined actuarially fair at margin if $\operatorname{TAX}(x)=0$. A pension system is defined to be quasi-actuarially fair at margin if $T A X(x)=0$ when $r=g_{f}$. If $T A X(x)>0$ the pension system imposes an implicit taxation on the continuation of the working activity; if $\operatorname{TAX}(x)<0$ it instead penalises early retirement.

\section{Results}

To compute PVR and TAX in alternative normative scenarios, we forecast appropriate conversion coefficients for future retirement years. These coefficients are reported in Appendix A. In scenarios $B_{2011}$ and $B_{1995}$, coefficients are expected to decrease considerably, as

\footnotetext{
${ }^{48}$ Therefore, the SSW for retirement ages at which the agent is not eligible for old-age or early retirement is computed conditional on being eligible for disability.
} 


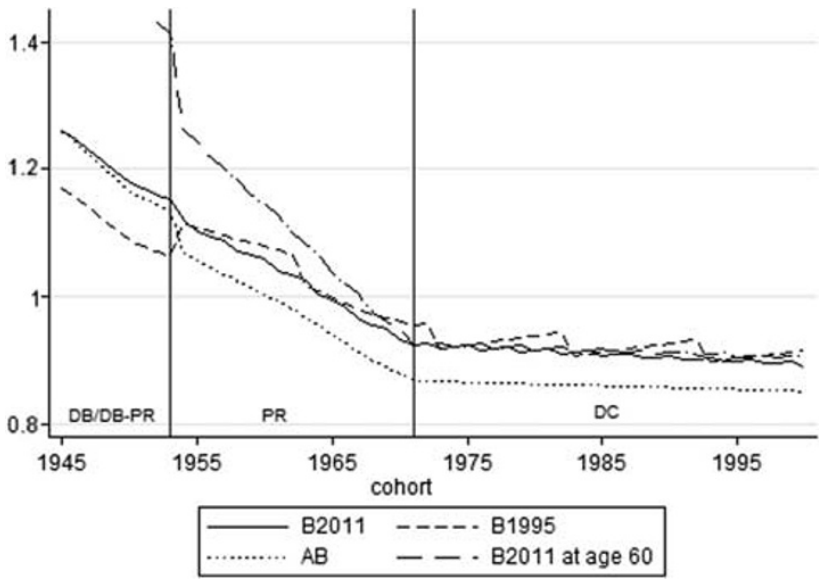

Figure 4. PVR by cohort: male white-collar workers, alternative scenarios.

Note: $B_{2011}$ : current pension rules; $B_{1995}$ : 1995 pension rules; $A B$ : quasi-actuarial benchmark; retirement at age 67 , $B_{2011}$ at age 60: current pension rules and retirement allowed at age $60 ; g_{f}=0.015, r=0.02$.

a consequence of the increased longevity; this especially occurs at older retirement ages and in the first years of the simulation (see Table A1). Cohort- and gender-specific conversion coefficients (scenario $A B$, Table A2) would be very heterogenous, with lower values expected for younger cohorts and females. Finally, a comparison between coefficients in scenarios $B_{2011}$ and $A B$ (see Table A3) shows that the former coefficients are higher than the latter by 5 to 10 percentage points for males and by 11 to 14 points for females. ${ }^{49}$

\section{Actuarial fairness}

Figure 4 reports the PVR by cohort for male white-collar workers retiring at age 67 (i.e. the future old-age retirement age, see the section "Institutional framework"). In addition to the normative scenarios $B_{2011}, B_{1995}$ and $A B$, the figure reports the case of hypothetical early retirement at age $60\left(B_{2011}\right.$ at age 60$)$; this case is reported to highlight the impact on the indicator of the stricter eligibility conditions introduced by the 2011 reform. ${ }^{50}$ The results for other agents and macroeconomic assumptions are described in the next section.

The DB-PR system turns out to be extremely generous, providing male white-collar agents with much more than actuarially fair benefits: employees born in 1945-1953 receive in terms of social security benefits up to 126 per cent of what they paid in terms of contributions during their working career $\left(\mathrm{PVR}=1.26\right.$ for cohort 1945 , scenario $\left.B_{2011}\right){ }^{51}$ Their PVR would

\footnotetext{
${ }^{49}$ Notice that the differences between the two scenarios decrease over time for males, while they remain almost constant for females. This different pattern can be explained by differences in our mortality projections between genders: although the rate of growth of life expectancy at old ages over cohorts is higher for males than for females, it declines faster for the former than for the latter gender.

${ }^{50}$ Given our assumptions, male white-collar workers are eligible for early retirement at age 66. Without the 2011 reform, the same workers would have been eligible for early retirement at age 60 .
} 
652

reach an even higher value, up to 1.4 , if they could claim benefits at age 60 as permitted before the 2011 reform $\left(B_{2011}\right.$ at age 60 , cf. with $\mathrm{PVR}=1.1$ scenario $B_{2011}$ cohort 1953$){ }^{52}$

Throughout the transitional phase towards the DC rules (cohorts 1954-1970), the PVR exhibits a decreasing trend due to the increasing weight of the DC quota in the computation of pension benefits of younger cohorts. For workers born after 1964, the system is less than actuarially fair. The stricter eligibility rules introduced in 2011 have a strong negative impact on the PVR for cohorts in the PR regime.

For workers born in 1971 or later, the PVR ranges between 0.89 and 0.93 , indicating that the steady-state DC regime is less than actuarially fair. This result is attributed to dynamic efficiency in NDC schemes. ${ }^{14}$ Noticeably, the PVR is 4-6 percentage points higher in scenario $B_{2011}$ than in scenario $A B$. This difference is the result of two counteracting effects, which stem from the specific rules adopted by the Italian law to handle increased and heterogeneous longevity. For one thing, pension computation disregards cohort effects in mortality; benefits of retirees are kept unchanged regardless of longevity changes occurred during retirement. This effect widens the gap between these two scenarios. For another, current pension rules penalise males by not accounting for their lower life expectancy, thus reducing this gap (for females, the difference in the PVR between scenarios $B_{2011}$ and $A B$ is much higher than for males, ranging between 10 and 13 percentage points: the two effects cumulate for females). Additional computations that violate dynamic efficiency (obtained setting $r=g_{f}=0.015$; results not reported) show that the PVR for the DC cohorts ranges between 1.05 and 1.09; this indicates that future DC pensions are expected to be more than quasi-actuarially fair (see the previous section).

Finally, Figure 4 shows that the PVR by cohort is characterised by an irregular course. Periodical adjustments of the conversion coefficients, implemented to counteract increased longevity, generate discontinuities in the indicator, revealing pension income redistribution between adjacent cohorts. Making revisions more frequent limits but does not eliminate this issue (cf. scenario $\mathrm{B}_{2011}$ and $B_{1995}$, i.e. revisions every 3 years vs 10 years). The PVR has a smooth course in the $A B$ scenario, where longevity increases are anticipated.

Figure 5 highlights the actuarial characteristics of disability benefits. It reports the PVR by claiming age (50 to 67) for male white-collar workers born in 1962, scenario $B_{2011}$. These agents become eligible for early retirement at age 66 ; between age 50 and 65 , we assume that they are eligible to claim disability benefits (see the section "Institutional framework"). The figure shows very high PVR for younger claiming ages, for example, at age 50, $\mathrm{PVR}=1.95$. It also shows a decline in the PVR with age,

${ }^{51}$ Notice that the PVR decreases by cohort even for cohorts in the old DB scheme (scenario $B_{1995}$ ). This is due to the increase in the payroll tax rate experienced by younger DB cohorts during their working career.

${ }^{52}$ Figure 4 also points out that the pro rata extension (from DB to DB-PR) introduced in 2011 increased the generosity of the pension system for cohorts $1945-1953$ (cf. $B_{2011}$ and $B_{1995}$ ). This partly compensates the negative effect on the indicator of stricter eligibility conditions imposed by the same reform ( $B_{2011}$ vs $B_{2011}$ at age 60). Such an increase in the PVR is explained with the feature of the DB-PR scheme of rewarding contributions paid during the whole working career; on the contrary, seniority was topped at 40 years in the former DB scheme (see the section "Institutional framework"). Notice that the value of the actuarial indicators for late male white-collar workers-claiming an old-age pension with 36 years of seniority-is almost unaffected by the implementation of the pro rata extension (see Appendix B). 


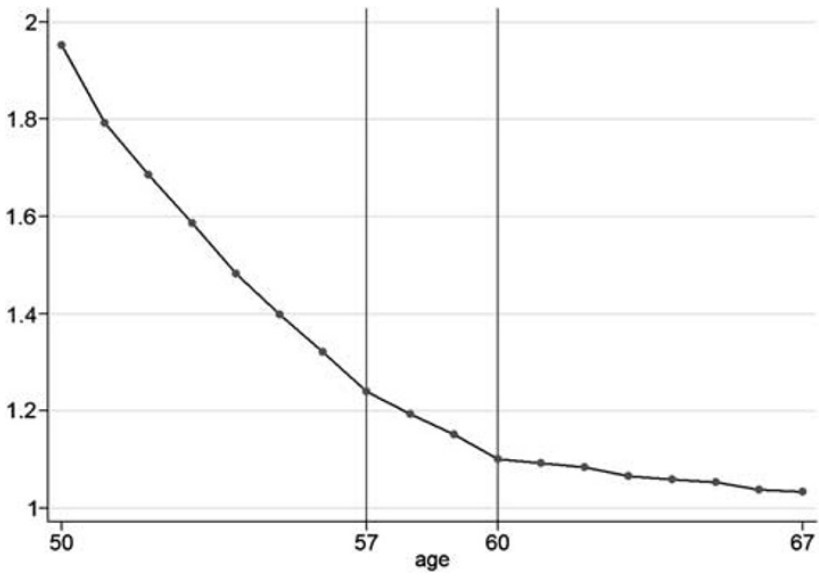

Figure 5. PVR by claiming age: male white-collar workers, cohort 1962.

Note: Scenario $B_{2011}$; cohort 1962 is aged 50 in 2012 and is subject to PR pension rules; $g_{f}=0.015, r=0.02$; these agents become eligible for early retirement at age 66 ; between age 50 and 65 , we assume that they are eligible to claim disability benefits.

characterised by two kinks at ages 57 and 60. As described in the section "Institutional framework", until age 60 disability pensions grant a "contributory bonus" and, up to age 57, their DC component is computed applying the favorable conversion coefficient established for age 57 (e.g. the PVR at age 50 would be equal to 1.74, instead of 1.95, if the coefficient for age 50 was applied). The size of these two "extra bonuses" diminishes as claiming age approaches 57 . Between ages 57 and 59, only the "contributory bonus" applies; for higher claiming ages, disability and old-age/early retirement benefits coincide, since no "extra bonus" is granted to disability benefits. ${ }^{53}$

\section{Actuarial fairness at margin}

Figure 6 shows the TAX by cohort for male white-collar workers retiring at age 67 . In the DB-PR scheme, the indicator reaches a value of 0.58 (scenario $B_{2011}$ ), which represents a strong financial incentive to claim pension benefits. ${ }^{54,55}$ The application of PR pension rules progressively reduces the implicit taxation of continuing working. In the steady state, the TAX ranges between 0.05 and 0.07 (excluding the spikes, see later), which is a very low value. Nevertheless, the implicit taxation is not eliminated. DC pensions are therefore less

\footnotetext{
53 The PVR at age 60 in Figure 5 is thus equal to that reported in Figure 4 for cohort 1962, scenario $B_{2011}$ at age 60. Up to age 59, the shape of the PVR by age is similar across the analysed cohorts. For retirement ages equal to 60 and above, the PVR decreases with the retirement age in the DB-PR and PR schemes, while it is almost constant with respect to it in the DC scheme (see Table B1).

54 Brugiavini (1999).

${ }^{55}$ Figure 6 also highlights that the pro-rata extension generates a relevant reduction in the TAX for older cohorts (cf. $B_{2011}$ and $B_{1995}$ ). As explained in footnote 52, the DC scheme allows for accumulation of pension rights beyond the $40^{\text {th }}$ year of work.
} 


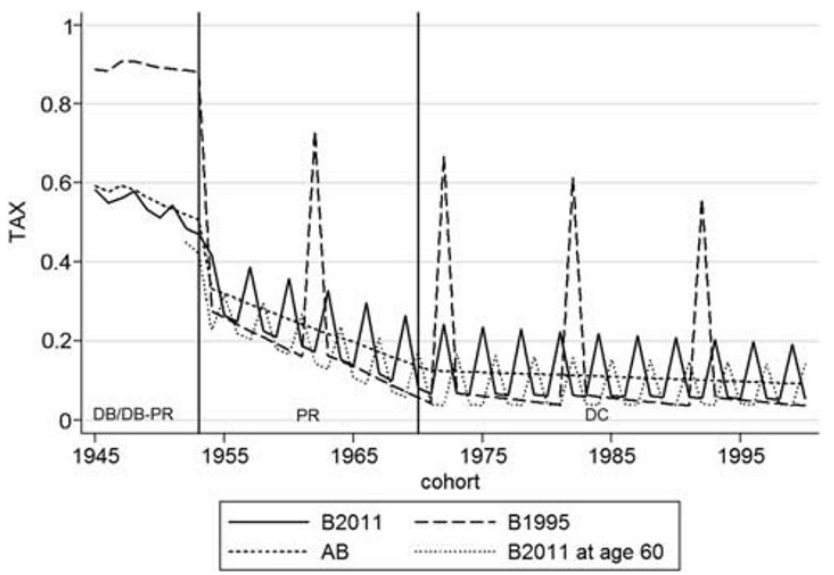

Figure 6. TAX by cohort: males white-collar workers, alternative scenarios. Note: see Figure 4.

than actuarially fair at margin: due to dynamic efficiency, it is optimal to retire at minimum requirements and invest the accumulated wealth in the financial market.

Finally, Figure 6 shows that the TAX is characterised by big spikes-equal to 14-17 percentage points - in the years preceding the revision of the conversion coefficients. An individual deciding in those years to work longer faces a very strong cut in his or her SSW. As expected, the more frequent the revision of the coefficients, the lower the generated spikes of taxation (cf. scenarios $B_{2011}$ and $B_{1995}$ ); however, spikes only disappear in scenario $A B$.

\section{Sensitivity}

In this section, we summarise the findings for alternative mortality projections, types of agent—see appendix B for details—and macroeconomic settings.

Figure 7 compares the PVR by cohort for male white-collar workers retiring at age 67 computed using our mortality forecasts (see Figure 4, scenario $B_{2011}$ ) with the corresponding values computed exploiting the probabilistic mortality projections for Italy implemented by the United Nations-percentiles 50, 80 and 20 (see the section "Projected cohort mortality tables"). ${ }^{56}$ The PVR computed using our life tables is $1-6$ percentage points lower than that computed with the UN tables-median. ${ }^{57}$ Projection uncertainty has a small impact on the

\footnotetext{
56 The whole set of results based on the UN life tables is available from the authors upon request.

57 These differences are not large. Consider that the UN longitudinal projections are more optimistic than ours with respect to the future evolution of life expectancy, especially at older ages. For instance, according to our tables, $e_{65}$ for males born in 1960 is equal to 22.1 years; the corresponding value according to the UN tablesmedian is equal to 24 years. Notice that these differences are not at odds with what reported in Figure 1, which refers to cross-sectional $e_{0}$.
} 


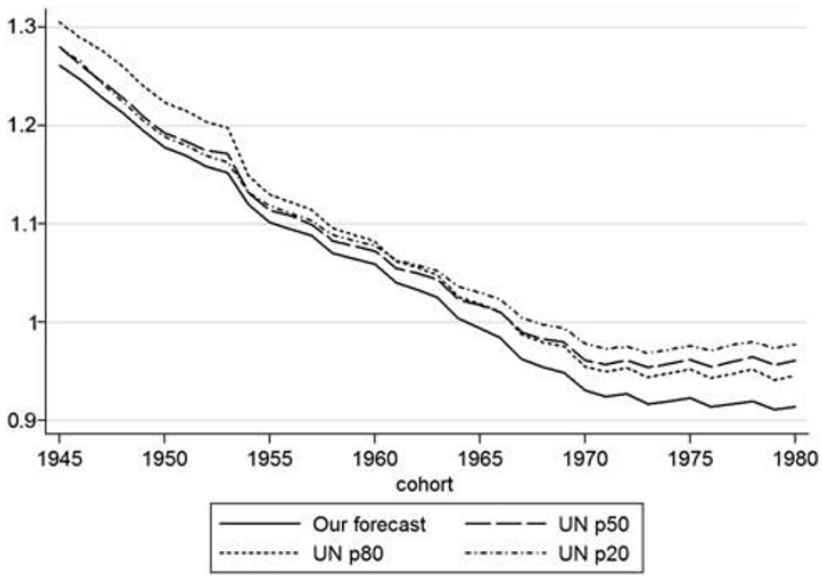

Figure 7. PVR by cohort: male white-collar workers, alternative mortality forecasts.

Note: scenario $B_{2011}$; retirement at age 67; UN p50, UN p80, UN p20: United Nations probabilistic projectionspercentiles 50, 80 and $20 ; g_{f}=0.015, r=0.02$.

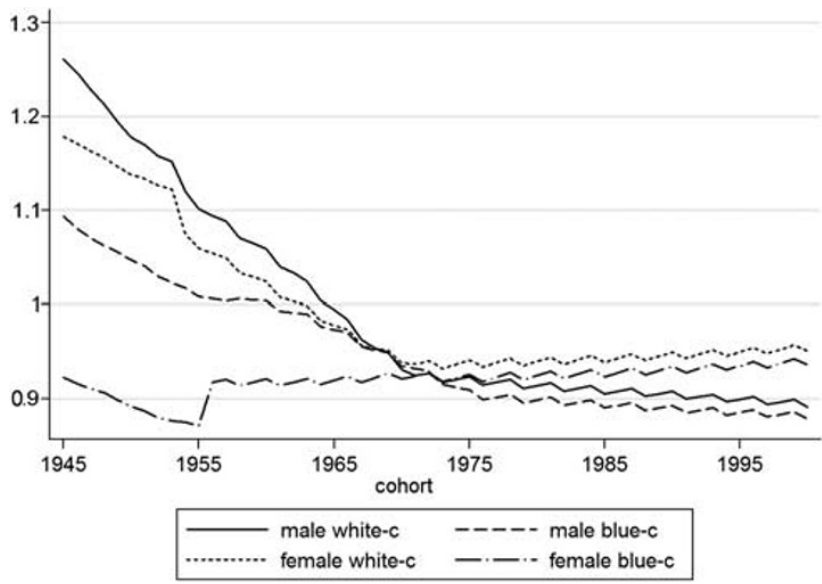

Figure 8. PVR by cohort at age 67: current legislation, different agents.

Note: scenario $B_{2011} ; g_{f}=0.015, r=0.02$.

PVR: for most of the cohorts, the difference in the PVR, UN percentiles 80 vs 20 , is lower than 4 percentage points; the maximum difference is equal to 6 percentage points, cohort 1980. This is an important finding, since our mortality projections are deterministic.

Our simplified within-cohort analysis largely confirms previous results from microsimulation models. ${ }^{58}$ Figure 8 compares the PVR by cohort at age 67 for male, females, blue- and

${ }^{58}$ See Marano et al. (2012); Borella and Coda Mascarola (2006). 
Table 3 Sensitivity analysis with respect to $g_{f}$ and $r$ : descriptive statistics

\begin{tabular}{|c|c|c|c|c|c|c|}
\hline & \multicolumn{2}{|c|}{$B_{2011}$} & \multicolumn{2}{|c|}{$B_{1995}$} & \multicolumn{2}{|c|}{$A B$} \\
\hline & $P V R$ & $T A X$ & $P V R$ & $T A X$ & $P V R$ & $T A X$ \\
\hline \multicolumn{7}{|c|}{ Cohort $1945(D B)$} \\
\hline Mean & 119.8 & 59.8 & 111.2 & 88.7 & 119.4 & 60.7 \\
\hline Sd & 19.4 & 3.5 & 18.1 & 1.5 & 19.3 & 3.4 \\
\hline Percentile 25 & 103.3 & 57.3 & 95.8 & 87.6 & 103.0 & 58.2 \\
\hline Percentile 50 & 115.7 & 59.8 & 107.4 & 89.0 & 115.4 & 60.7 \\
\hline Percentile 75 & 133.3 & 62.4 & 123.9 & 90.0 & 133.0 & 63.2 \\
\hline \multicolumn{7}{|c|}{ Cohort 2000 (NDC) } \\
\hline Mean & 78.4 & 9.3 & 80.5 & 7.7 & 74.7 & 12.8 \\
\hline $\mathrm{Sd}$ & 14.6 & 5.6 & 14.9 & 5.8 & 14.1 & 5.1 \\
\hline Percentile 25 & 66.7 & 4.8 & 68.7 & 3.0 & 63.1 & 8.6 \\
\hline Percentile 50 & 79.2 & 8.8 & 81.4 & 7.3 & 75.5 & 12.4 \\
\hline Percentile 75 & 90.1 & 13.6 & 92.7 & 12.1 & 85.2 & 16.8 \\
\hline
\end{tabular}

Note: Percentage points; male white-collar workers retiring at age $67 ; r \in[0.01,0.03], g_{f} \in[0.005,0.025], r>g_{f}$.

white-collar workers. In the DB-PR scheme, the highest PVR is found for white-collar workers (steeper age-wage profiles), whereas the lowest is found for blue-collar workers (flatter profiles). This result is attributed to the DB pension formula, which only accounts for the last wages before retirement. Since individuals with steeper age-wage profiles are typically also the richer, the DB system is known to redistribute resources in a "perverse" way. ${ }^{59}$ In the DC scheme, the highest PVR is found for (longer-living) female workers. ${ }^{17}$

The heterogeneous effects of the normative changes implemented in 2011 are worth mentioning. Previous studies report $P V R>1$ for almost all workers in the $\mathrm{DB}$ scheme retiring at younger (pre-2011) retirement ages. ${ }^{60}$ Figure 8 shows instead $P V R<1$ for older cohorts of female blue-collar workers. More generally, our computations highlight that the DB-PR scheme is less than actuarially fair $(P V R<1$, see Table B1) for workers who retire at later ages and whose age-wage profiles is approximately flat.

Finally, we run a robustness check of main findings with respect to alternative macroeconomic conditions: we draw vectors $\left[g_{f}, r\right]$ from a bivariate continuous uniform distribution $-g_{f} \in[0.005,0.025], r \in[0.01,0.03]$ - and recompute PVR and TAX accordingly. The qualitative effect of the two macroeconomic variables on the indicators can be determined a priori: $\partial P V R / \partial r<0, \partial P V R / \partial g_{f} \geqslant 0, \partial T A X / \partial r>0, \partial T A X / \partial g_{f} \leqslant 0 .{ }^{61}$ Table 3 reports summary statistics of this exercise for male white-collar workers retiring at age 67, cohorts 1945 (DB) and 2000 (DC), alternative scenarios $\left(B_{2011}, B_{1995}, A B\right)$. The median PVR (TAX) are lower (higher) than in the base case, since in most drawn vectors $r-g_{f}>0.5$ per cent. The interquartile range is quite

${ }^{59}$ Coda Moscarola and Fornero (2009).

${ }^{60}$ See e.g. Borella and Coda Moscarola (2006).

$61 \partial P V R / \partial r<0$ : both PVB+PVW and PVC (see equation 8) decrease if $r$ increases, but the impact on the former is stronger than on the latter; $\partial P V R / \partial g_{f} \geqslant 0$ : if $g_{f}$ increases $\mathrm{PVB}+\mathrm{PVW}$ increases due to an increase in $P($.) in the DC scheme; $\partial T A X / \partial r>0: r$ is the opportunity-cost to stay at work; $\partial T A X / \partial g_{f} \leqslant 0: g_{f}$ is the opportunity-cost to retire in the DC scheme. 
small for the TAX (e.g. 62.4-57.3=5.1 percentage points, 1945 cohort, scenario $B_{2011}$ ). In the DC scheme, $P V R<1$ and $T A X>0$ in almost all the cases. Qualitatively, the results found for the base macroeconomic setting remain valid for a wide range of macroeconomic conditions. A noticeable exception occurs however for the PVR -1945 cohort scenario $B_{1995}$, which is lower than one in more than 25 per cent of the cases.

\section{Conclusions}

This study analyses the actuarial characteristics of the Italian pension system throughout its transition from DB to NDC rules, taking into account expected increasing longevity. Computations rely on ad hoc projected cohort mortality tables based on a limit survival scenario depicted by demographic experts.

Most workers retiring in the coming years, whose pension is partly computed according to the DB rules, will receive more-than-actuarially fair pensions. However, the generosity of the pension system has been significantly reduced for them by a recent reform which tightened eligibility requirements for early retirement. As a consequence of these normative changes, those workers who retire at later ages and whose age-wage profiles is approximately flat will receive less-than-actuarially fair benefits. Disability benefits remain (extremely) generous when claimed before age (57) 60.

Steady-state NDC pensions, due to dynamic efficiency, are less than actuarially fair (at margin). They further deviate from actuarial fairness due to the specific rules adopted by the Italian law to handle expected increasing and heterogeneous longevity: pensions computation disregards cohort effects in mortality and benefits of retirees are kept unchanged regardless of longevity changes occurred during retirement. Periodical revisions of the pension formula, implemented to counteract increased longevity, generate sizeable redistribution between cohorts as well as strong financial incentives to retire in the year preceding each revision. The use of unisex pension rules favors longer-living females and penalise males.

Cohort mortality projections should be used to handle longevity increases in NDC schemes. This would avoid actuarial shortcomings and related cohort redistribution stemming from alternative procedures based on historical mortality, such as the one implemented in Italy.

\section{References}

Aaron, H. (1966) 'The social insurance paradox', Canadian Journal of Economics and Political Science 32(3): 371-374

Belloni, M. and Alessie, R. (2009) 'The importance of financial incentives on retirement choices: New evidence for Italy', Labour Economics 16(5): 578-588.

Bengtsson, T. and Keilman, N. (eds) (2003) Perspectives on Mortality Forecasting, Social Insurance Studies No. 1, Stockholm, Sweden: Riksfrskringsverket (RFV).

Booth, H. and Tickle, L. (2008) Mortality modelling and forecasting: A review of methods, ADSRI Working Paper No. 3, from http://adsri.anu.edu.au/.

Borella, M. and Coda Moscarola, F. (2006) 'Distributive properties of pension systems: A simulation of the Italian transition from defined benefit to notional defined contribution', Giornale degli Economisti e Annali di Economia 65(1): 95-125.

Brass, W. (1971) On the Scale of Mortality, Biological Aspects of Demography, London: Taylor and Francis. 
Brugiavini, A. (1999) 'Social Security and Retirement in Italy', in J. Gruber and D. Wise (eds) Social Security and Retirement Around the World, Chicago: University of Chicago Press, pp 181-237.

Brugiavini, A. and Galasso, V. (2004) 'The social security reform process in Italy: Where do we stand?' Journal of Pension Economics and Finance 3(2): 165-195.

Caselli, G., Peracchi, F., Barbi, E. and Lipsi, R. (2003) 'Differential mortality and the design of the Italian system of public pensions', Labour 17(S1): 45-78, Supplement.

Chlon, A., Gora, M. and Rutkowski, M. (1999) 'Shaping pension reform in Poland: Security through diversity', World Bank Social Protection Discussion Paper Series, No. 9923.

Christensen, K., Doblhammer, G., Rau, R. and Vaupel, J. (2009) 'Ageing populations: The challenges ahead', The Lancet 374: 1196-1208.

Coda Moscarola, F. and Fornero, E. (2009) 'How to strengthen the credibility of the Italian pension system', The Geneva Papers on Risk and Insurance -Issues and Practice 34(4): 591-601.

COVIP (Commisione di Vigilanza sui Fondi Pensione) (2011) "Relazione per l'Anno 2011".

Disney, R. (2004) ‘Are contributions to public pension programmes a tax on employment?' Economic Policy 19(39): 267-300.

Duchêne, J. and Wunsch, G. (1993) "Population Aging and the Limits to Human Life", in W. Lutz. (ed.) Future Demographic Trends in Europe and North America: What Can We Assume Today, London: Academic Press, pp. 27-40.

Dugan, C., Gulumser, H., Humble, R. and Ryan, D. (2005) 'Analysis of Trends in the Age-Specific Shape of Mortality Curves for Populations in the United States and Japan', Paper presented at the Living to 100 and Beyond Symposium, sponsored by the Society of Actuaries, Orlando, FL, 12-14 January.

EPC-WGA (2011) 'The 2012 ageing report: Underlying assumptions and projections methodologies,' European Economy No. 4, European Policy Committee-European Commission.

Ferraresi, P. and Fornero, E. (2000) Social security transition in Italy: Costs, distortions and (some) possible corrections, CeRP Working Paper No. 2.

Fornero, E and Castellino, O. (2001) La Riforma del Sistema Previdenziale Italiano, Bologna: Il Mulino.

Fries, J. (1983) 'The compression of morbidity', The Milbank Memorial Fund Quarterly 61(3): 397-419.

Fries, J. (1989) 'The compression of morbidity: Near or far?' The Milbank Quarterly 67(2): 208-232.

Heckman, J. and Robb, R. (1985) 'Using longitudinal data to estimate age, period and cohort effects in earnings equations', in W. Mason and S. Fienberg (eds) Cohort Analysis in Social Research: Beyond the Identification Problem, New York: Springer-Verlag.

Holzmann, R. (2006) 'Toward a coordinated pension system in Europe: Rationale and potential structure', in R. Holzmann and E. Palmer (eds) Pension Reform: Issues and Prospects for Non-Financial Defined Contribution (NDC) Schemes. Chapter 11, Washington, DC: The World Bank, pp. 225-265.

ISTAT (2006) 'Matrimoni, Separazioni e Divorzi, Anno 2002'.

ISTAT (2007) 'Cause di Morte, Anno 2002'.

ISTAT (2008) 'Previsioni Demografiche 1.1.2007-1.1.2051', M. Marsili and M.P. Sorvillo (eds), from www.demo.istat.it. ISTAT (2010) 'Tavole di Mortalità della popolazione italiana per provincia e regione di residenza - demo.istat.it'.

Johnson, N. and Kotz, S. (1970) Distributions in Statistics-Continuous Univariate Distributions, Vol. 1, 1st edn, New York: Wiley and Sons.

Kannisto, V. (1996) The Advancing Frontier of Survival. Odense Monographs on Population Aging, 3rd edn, Odense, Denmark: Odense University Press.

Kapteyn, A., Alessie, R. and Lusardi, A. (2005) 'Explaining the wealth holdings of different cohorts: Productivity growth and Social Security', European Economic Review 49(5): 1361-1391.

Lee, R. and Carter, L. (1992) 'Modeling and forecasting U.S. mortality', Journal of the American Statistical Association 87(419): 659-671.

Legros, F. (2006) 'NDCs: A Comparison of the French and German Point Systems', in R. Holzmann and E. Palmer (eds) Pension Reform: Issues and Prospects for Non-Financial Defined Contribution (NDC) Schemes. Chapter 10, Washington, DC: The World Bank, pp. 203-222.

Li, N. and Gerland, P. (2012) 'Modifying the Lee-Carter method to project mortality changes up to 2100', paper presented at the Population Association of America 2011 Annual Meeting-Washington, DC. Session 125: Formal Demography I: Mathematical Models and Methods.

Lindbeck, A. (2006) 'Conceptualization of Non-financial Defined Contribution Systems', in R. Holzmann and E. Palmer (eds) Pension Reform: Issues and Prospects for Non-Financial Defined Contribution (NDC) Schemes. Chapter 5, Washington, DC: The World Bank, pp. 71-75. 
Maccheroni, C. (1998) 'Frontiere della Sopravvivenza più Vicine? Alcuni Risultati Tratti dalla Recente Esperienza Italiana', Diritto ed Economia dell'Assicurazione 40(4): 783-805.

Maccheroni, C. and Locatelli, I. (1999) 'I Grandi Anziani: Evoluzione del Fenomeno in Italia alla Luce del Metodo delle Generazioni Estinte', Rivista Italiana di Economia, Demografia e Statistica 53(1): 37-61.

Marano, A., Mazzaferro, C. and Morciano, M. (2012) 'The strengths and failures of incentives mechanisms in notional defined contribution pension systems', Giornale degli Economisti e Annali di Economia 71(1): 33-70.

Mazzaferro, C., Morciano, M. and Savegnago, M. (2012) 'Differential mortality and redistribution in the Italian notional defined contribution system', Journal of Pension Economics and Finance 11(4): 500-530.

MEF (2009) 'Mid-long Term Trends for the Pension, Health and Long-Term Care Systems', Ministry of Economy and Finance, Report No. 11, Summary and Conclusions.

MEF (2011) 'Mid-long Term Trends for the Pension, Health and Long-Term Care Systems', Ministry of Economy and Finance, Report No.12, Summary and Conclusions.

Myers, G. and Manton, K. (1984) 'Compression of mortality: Myth or reality?' The Gerontologist 24(4): 346-353.

Nizard, A. and Vallin, J. (1970) 'Les plus faibles mortalités', Population 25(4): 847-874.

NVSP (2006) 'Metodologia di calcolo dei coefficienti', Delibera9, Ministry of Labor and Welfare Policies.

Olshanski, S., Carnes, B. and Cassel, C. (1993) 'The ageing of the human species', Scientific America 268(4): 46-52.

Palmer, E. (2000) "The Swedish Pension Reform Model: Framework and Issues", World Bank Social Protection Discussion Paper Series, No. 23086.

Palmer, E. (2006) 'What is NDC?' in R. Holzmann and E. Palmer (eds) Pension Reform: Issues and Prospects for Non-Financial Defined Contribution (NDC) Schemes, Chapter 2, Washington, DC: The World Bank, pp. 17-33.

Palmer, E., Stabina, S., Svensson, I. and Vanovska, I. (2006) 'NDC Strategy in Latvia: Implementation and Prospects for the Future', in R. Holzmann and E. Palmer (eds) Pension Reform: Issues and Prospects for NonFinancial Defined Contribution (NDC) Schemes. Chapter 15, Washington, DC: The World Bank, pp. $397-424$.

Pollard, J. (1987) 'Projection of age-specific mortality rates', Population Bulletin of the United Nations 21(22): 55-69.

Queisser, M. and Whitehouse, E.R. (2006) 'Neutral or fair?: Actuarial concepts and pension-system design', OECD Social, Employment and Migration Working Paper No. 40, Paris: OECD Publishing.

Raftery, A., Li, N., Ševčíková, H., Gerland, P. and Heilig, G. (2012) 'Bayesian probabilistic population projections for all countries', Proceedings of the National Academy of Sciences of the United States of America 109(35): $13915-13921$.

Raftery, A.E., Chunn, J., Gerland, P. and Ševčíková, H. (2013) 'Bayesian probabilistic projections of life expectancy for all countries', Demography 50(3): 777-801.

Robine, J. and Cheung, S. (2008) 'Nouvelles observations sur la longévité humaine', Revue économique 59(5): 941-954.

Robine, J.-M., Crimmins, E., Horiuchi, S. and Zeng, Y. (2006) Human Longevity, Individual Life Duration, and the Growth of the Oldest-Old Population International Studies in Population, Vol. 4, New York: Springer.

Samuelson, P. (1958) 'An exact consumption-loan model of interest with or without the social contrivance of money', Journal of Political Economy 66(6): 467-482.

Tabeau, E., van den Berg Jeths, A and Heathcote, C. (2002) Forecasting Mortality in Developed Countries: Insights from a Statistical, Demographic and Epidemiological Perspective, of European Studies of Population, Vol. 9 , Dordrecht: EAPS-Kluwer Academic Publishers.

UN (2012) 'Probabilistic Population Projections', Population Division of the (DESA) UN Department of Economic and Social Affairs (DESA), from www.esa.un.org/unpd/ppp/index.htm.

Wilmoth, J.R. (2000) 'Demography of longevity: Past, present and future trends', Experimental Gerontology 35(9-10): 1111-1129.

Wilmoth, J. and Lundstrom, H. (1996) 'Extreme longevity in five countries: Presentation of trends with special attention to issues of date quality', European Journal of Population 12(1): 63-93.

Wilmoth, J. and Robine, J. (2003) 'The world trend in maximum life span', Population and Development Review 29(Suppl): 239-257. 


\section{Appendix A}

\section{Forecasted conversion coefficients}

Table A1 Legislated and forecasted conversion coefficients (percentage points) by retirement age and year: current legislation

\begin{tabular}{|c|c|c|c|c|c|c|}
\hline \multirow[t]{3}{*}{ Age } & \multicolumn{6}{|c|}{ Retirement year (life tables) } \\
\hline & $1995-09$ & $2010-12$ & $2019-21$ & $2028-30$ & $2040-42$ & $2049-51$ \\
\hline & (ISTAT90) & (ISTAT02) & $(2018)$ & (2027) & $(2039)$ & $(2048)$ \\
\hline 57 & 4.720 & 4.419 & 4.169 & 4.029 & 3.866 & 3.758 \\
\hline 58 & 4.860 & 4.538 & 4.276 & 4.128 & 3.956 & 3.843 \\
\hline 59 & 5.006 & 4.664 & 4.390 & 4.234 & 4.052 & 3.932 \\
\hline 60 & 5.163 & 4.798 & 4.511 & 4.345 & 4.153 & 4.027 \\
\hline 61 & 5.334 & 4.940 & 4.640 & 4.464 & 4.261 & 4.127 \\
\hline 62 & 5.514 & 5.093 & 4.777 & 4.590 & 4.375 & 4.233 \\
\hline 63 & 5.706 & 5.257 & 4.922 & 4.724 & 4.496 & 4.346 \\
\hline 64 & 5.911 & 5.432 & 5.077 & 4.867 & 4.625 & 4.466 \\
\hline 65 & 6.136 & 5.620 & 5.244 & 5.020 & 4.762 & 4.594 \\
\hline 66 & - & - & 5.422 & 5.183 & 4.909 & 4.787 \\
\hline 67 & - & - & 5.613 & 5.358 & 5.066 & 4.937 \\
\hline 68 & - & - & 5.818 & 5.546 & 5.235 & 5.032 \\
\hline 69 & - & - & 6.040 & 5.749 & 5.417 & 5.200 \\
\hline 70 & - & - & 6.278 & 5.964 & 5.612 & 5.381 \\
\hline
\end{tabular}

Note: First two columns show coefficients applied respectively to the retirement periods 1995-2009 and 2010-12 (Law No. 335/95 and Law No. 247/07); following columns show forecasted conversion coefficients for selected retirement years (retirement ages 57-62 are displayed for comparison with first column); coefficients are computed using forecasted cross-sectional life tables for the year indicated in italics at the top of each column. 
Michele Belloni and Carlo Maccheroni Actuarial Fairness When Longevity Increases

661

Table A2 Forecasted conversion coefficients (percentage points) by retirement age and genderselected cohort: $A B$ scenario

\begin{tabular}{|c|c|c|c|c|c|c|}
\hline \multirow[t]{3}{*}{ Age } & \multicolumn{6}{|c|}{ Cohort } \\
\hline & \multicolumn{3}{|c|}{ Males } & \multicolumn{3}{|c|}{ Females } \\
\hline & 1950 & 1970 & 1990 & 1950 & 1970 & 1990 \\
\hline 57 & 4.044 & 3.769 & 3.557 & 3.925 & 3.627 & 3.375 \\
\hline 58 & 4.140 & 3.851 & 3.629 & 4.014 & 3.701 & 3.437 \\
\hline 59 & 4.240 & 3.939 & 3.706 & 4.108 & 3.779 & 3.503 \\
\hline 60 & 4.347 & 4.031 & 3.787 & 4.208 & 3.862 & 3.571 \\
\hline 61 & 4.459 & 4.128 & 3.872 & 4.313 & 3.949 & 3.643 \\
\hline 62 & 4.578 & 4.231 & 3.961 & 4.425 & 4.041 & 3.719 \\
\hline 63 & 4.704 & 4.339 & 4.056 & 4.543 & 4.137 & 3.800 \\
\hline 64 & 4.837 & 4.454 & 4.156 & 4.668 & 4.240 & 3.884 \\
\hline 65 & 4.978 & 4.575 & 4.262 & 4.802 & 4.348 & 3.973 \\
\hline 66 & 5.129 & 4.705 & 4.374 & 4.943 & 4.464 & 4.068 \\
\hline 67 & 5.290 & 4.842 & 4.494 & 5.094 & 4.586 & 4.169 \\
\hline 68 & 5.462 & 4.989 & 4.621 & 5.256 & 4.717 & 4.276 \\
\hline 69 & 5.647 & 5.146 & 4.757 & 5.429 & 4.857 & 4.390 \\
\hline 70 & 5.845 & 5.315 & 4.902 & 5.613 & 5.006 & 4.511 \\
\hline
\end{tabular}

Table A3 Forecasted conversion coefficients: percentage deviation between current legislation (Table A1) and AB scenario (Table A2)

\begin{tabular}{|c|c|c|c|c|c|c|c|c|c|c|}
\hline \multirow[t]{3}{*}{ Age } & \multicolumn{10}{|c|}{ Retirement year } \\
\hline & \multicolumn{5}{|c|}{ Males } & \multicolumn{5}{|c|}{ Females } \\
\hline & 2010 & 2020 & 2030 & 2040 & 2050 & 2010 & 2020 & 2030 & 2040 & 2050 \\
\hline 57 & 10.5 & 8.1 & 7.9 & 6.6 & 6.5 & 14.1 & 12.0 & 12.3 & 11.7 & 12.5 \\
\hline 58 & 10.5 & 8.1 & 7.9 & 6.6 & 6.5 & 14.1 & 12.0 & 12.4 & 11.8 & 12.6 \\
\hline 59 & 10.4 & 8.0 & 7.8 & 6.5 & 6.7 & 14.1 & 12.1 & 12.5 & 11.8 & 12.7 \\
\hline 60 & 10.4 & 8.0 & 7.8 & 6.4 & 6.3 & 14.0 & 12.1 & 12.5 & 11.9 & 12.8 \\
\hline 61 & 10.3 & 7.9 & 7.8 & 6.4 & 6.3 & 14.1 & 12.1 & 12.6 & 11.9 & 12.8 \\
\hline 62 & 10.3 & 7.9 & 7.7 & 6.3 & 6.2 & 14.1 & 12.2 & 12.6 & 12.0 & 12.9 \\
\hline 63 & 10.2 & 7.8 & 7.7 & 6.2 & 6.1 & 14.1 & 12.2 & 12.7 & 12.0 & 12.9 \\
\hline 64 & 10.2 & 7.8 & 7.6 & 6.1 & 6.1 & 14.1 & 12.2 & 12.7 & 12.0 & 13.0 \\
\hline 65 & 10.2 & 7.7 & 7.6 & 6.1 & 6.0 & 14.1 & 12.2 & 12.8 & 12.0 & 13.0 \\
\hline 66 & - & 7.7 & 7.5 & 6.0 & 7.2 & - & 12.2 & 12.8 & 12.1 & 14.5 \\
\hline 67 & - & 7.6 & 7.5 & 5.9 & 7.2 & - & 12.2 & 12.8 & 12.1 & 14.6 \\
\hline 68 & - & 7.6 & 7.4 & 5.8 & 5.7 & - & 12.1 & 12.8 & 12.1 & 13.2 \\
\hline 69 & - & 7.5 & 7.4 & 5.7 & 5.7 & - & 12.1 & 12.8 & 12.1 & 13.2 \\
\hline 70 & - & 7.4 & 7.2 & 5.6 & 5.6 & - & 11.9 & 12.8 & 12.1 & 13.3 \\
\hline
\end{tabular}




\section{Appendix B}

Table B1 PVR by selected cohort and retirement age-alternative normative scenarios and types of worker

\begin{tabular}{|c|c|c|c|c|c|c|c|}
\hline \multicolumn{8}{|c|}{ Scenario: $B_{1995}$} \\
\hline \multicolumn{2}{|c|}{ Cohort/Scheme } & \multicolumn{6}{|c|}{ Retirement age } \\
\hline & & 55 & 57 & 60 & 63 & 65 & 67 \\
\hline \multicolumn{8}{|c|}{ Male white-collar } \\
\hline 1945 & DB/DB-PR & - & - & - & - & - & 117.0 \\
\hline 1950 & DB/DB-PR & - & - & - & 133.5 & 122.0 & 108.7 \\
\hline 1955 & PR & - & 143.9 & 126.6 & 121.4 & 113.3 & 110.9 \\
\hline 1960 & PR & 149.3 & 133.2 & 114.0 & 110.7 & 109.1 & 108.0 \\
\hline 1965 & PR & 130.3 & 116.6 & 105.5 & 104.5 & 100.1 & 99.8 \\
\hline 1970 & PR & 118.6 & 106.4 & 94.1 & 94.7 & 95.3 & 96.1 \\
\hline 1975 & $\mathrm{DC}$ & 113.4 & 101.8 & 93.7 & 94.7 & 91.6 & 92.3 \\
\hline 1980 & $\mathrm{DC}$ & 114.9 & 103.2 & 91.5 & 92.3 & 93.0 & 93.8 \\
\hline 1985 & $\mathrm{DC}$ & 112.4 & 101.0 & 92.7 & 93.6 & 90.7 & 91.2 \\
\hline 1990 & $\mathrm{DC}$ & 113.7 & 102.2 & 90.8 & 91.4 & 92.0 & 92.6 \\
\hline 1995 & $\mathrm{DC}$ & 111.5 & 100.3 & 91.9 & 92.7 & 89.8 & 90.2 \\
\hline 2000 & $\mathrm{DC}$ & 112.7 & 101.4 & 90.1 & 90.6 & 91.0 & 91.4 \\
\hline \multicolumn{8}{|c|}{ Late male white-collar } \\
\hline 1945 & DB/DB-PR & - & - & - & - & - & 119.9 \\
\hline 1950 & $\mathrm{PR}$ & - & - & - & 121.8 & 118.3 & 115.7 \\
\hline 1955 & PR & - & 136.5 & 119.8 & 115.9 & 108.3 & 106.5 \\
\hline 1960 & PR & 141.5 & 125.4 & 106.5 & 104.6 & 103.8 & 103.5 \\
\hline 1965 & PR & 122.4 & 108.7 & 98.5 & 99.0 & 95.1 & 95.6 \\
\hline 1970 & PR & 118.8 & 105.8 & 92.7 & 93.7 & 94.5 & 95.4 \\
\hline 1975 & $\mathrm{DC}$ & 116.1 & 103.4 & 94.2 & 95.2 & 91.9 & 92.6 \\
\hline 1980 & DC & 117.6 & 104.8 & 92.0 & 92.8 & 93.4 & 94.1 \\
\hline 1985 & $\mathrm{DC}$ & 115.1 & 102.6 & 93.3 & 94.1 & 91.1 & 91.7 \\
\hline 1990 & $\mathrm{DC}$ & 116.4 & 103.9 & 91.3 & 91.9 & 92.4 & 93.0 \\
\hline 1995 & $\mathrm{DC}$ & 114.2 & 101.9 & 92.5 & 93.2 & 90.3 & 90.7 \\
\hline 2000 & $\mathrm{DC}$ & 115.4 & 103.1 & 90.7 & 91.1 & 91.5 & 91.9 \\
\hline \multicolumn{8}{|c|}{ Male blue-collar } \\
\hline 1945 & DB/DB-PR & - & - & - & - & - & 92.8 \\
\hline 1950 & DB/DB-PR & - & - & - & 113.7 & 100.8 & 89.5 \\
\hline 1955 & DB/DB-PR & - & 156.1 & 131.1 & 109.9 & 97.7 & 86.9 \\
\hline 1960 & PR & 143.4 & 128.7 & 110.9 & 106.4 & 104.0 & 102.2 \\
\hline 1965 & PR & 129.2 & 116.5 & 105.9 & 103.5 & 98.7 & 97.7 \\
\hline 1970 & PR & 120.4 & 109.0 & 97.4 & 96.6 & 96.3 & 96.2 \\
\hline 1975 & $\mathrm{DC}$ & 108.5 & 98.6 & 92.5 & 93.5 & 90.2 & 90.9 \\
\hline 1980 & $\mathrm{DC}$ & 109.8 & 99.8 & 90.2 & 90.9 & 91.5 & 92.2 \\
\hline 1985 & $\mathrm{DC}$ & 107.4 & 97.7 & 91.4 & 92.2 & 89.2 & 89.7 \\
\hline 1990 & $\mathrm{DC}$ & 108.6 & 98.9 & 89.5 & 90.1 & 90.5 & 91.1 \\
\hline 1995 & $\mathrm{DC}$ & 106.5 & 97.0 & 90.6 & 91.3 & 88.5 & 88.8 \\
\hline 2000 & $\mathrm{DC}$ & 107.6 & 98.1 & 88.9 & 89.3 & 89.7 & 90.1 \\
\hline
\end{tabular}


Table B1 (continued)

\begin{tabular}{|c|c|c|c|c|c|c|c|}
\hline \multicolumn{2}{|c|}{ Cohort/Scheme } & \multicolumn{6}{|c|}{ Retirement age } \\
\hline & & 55 & 57 & 60 & 63 & 65 & 67 \\
\hline \multicolumn{8}{|c|}{ Female white-collar } \\
\hline 1945 & DB/DB-PR & - & - & - & - & - & 109.6 \\
\hline 1950 & DB/DB-PR & - & - & - & 131.1 & 119.7 & 106.4 \\
\hline 1955 & $\mathrm{PR}$ & - & 139.9 & 123.2 & 117.8 & 109.7 & 106.6 \\
\hline 1960 & PR & 144.8 & 129.9 & 111.5 & 108.0 & 106.0 & 104.4 \\
\hline 1965 & PR & 128.2 & 115.3 & 104.6 & 103.4 & 98.9 & 98.2 \\
\hline 1970 & PR & 119.2 & 107.4 & 95.3 & 95.9 & 96.3 & 96.9 \\
\hline 1975 & $\mathrm{DC}$ & 114.6 & 103.4 & 95.7 & 96.8 & 93.5 & 94.1 \\
\hline 1980 & $\mathrm{DC}$ & 116.5 & 105.3 & 94.0 & 94.9 & 95.6 & 96.4 \\
\hline 1985 & $\mathrm{DC}$ & 114.4 & 103.5 & 95.7 & 96.9 & 93.9 & 94.6 \\
\hline 1990 & $\mathrm{DC}$ & 116.2 & 105.2 & 94.2 & 95.3 & 96.0 & 96.9 \\
\hline 1995 & $\mathrm{DC}$ & 114.4 & 103.7 & 96.0 & 97.2 & 94.6 & 95.3 \\
\hline 2000 & $\mathrm{DC}$ & 116.3 & 105.5 & 94.8 & 95.9 & 96.7 & 97.6 \\
\hline \multicolumn{8}{|c|}{ Female blue-collar } \\
\hline 1945 & DB/DB-PR & - & - & - & - & - & 81.8 \\
\hline 1950 & DB/DB-PR & - & - & - & 104.6 & 91.4 & 79.7 \\
\hline 1955 & DB/DB-PR & - & 142.2 & 117.6 & 102.0 & 89.5 & 78.4 \\
\hline 1960 & $\mathrm{PR}$ & 133.4 & 119.2 & 102.3 & 98.1 & 95.8 & 93.8 \\
\hline 1965 & PR & 122.0 & 109.9 & 100.1 & 98.1 & 93.4 & 92.3 \\
\hline 1970 & PR & 117.0 & 106.2 & 95.3 & 95.0 & 94.9 & 94.9 \\
\hline 1975 & DC & 110.4 & 100.5 & 94.5 & 95.5 & 92.1 & 92.5 \\
\hline 1980 & $\mathrm{DC}$ & 112.2 & 102.3 & 92.9 & 93.7 & 94.2 & 94.9 \\
\hline 1985 & $\mathrm{DC}$ & 110.2 & 100.5 & 94.6 & 95.6 & 92.5 & 93.1 \\
\hline 1990 & $\mathrm{DC}$ & 111.9 & 102.2 & 93.1 & 94.0 & 94.6 & 95.3 \\
\hline 1995 & $\mathrm{DC}$ & 110.2 & 100.8 & 94.9 & 95.9 & 93.2 & 93.8 \\
\hline 2000 & DC & 112.0 & 102.5 & 93.6 & 94.6 & 95.3 & 96.1 \\
\hline
\end{tabular}

Scenario: $B_{2011}$

\begin{tabular}{|c|c|c|c|c|c|c|c|}
\hline \multicolumn{2}{|c|}{ Cohort/scheme } & \multicolumn{6}{|c|}{ Retirement age } \\
\hline & & 55 & 57 & 60 & 63 & 65 & 67 \\
\hline \multicolumn{8}{|c|}{ Male white-collar } \\
\hline 1945 & DB/DB-PR & - & - & - & - & - & 126.1 \\
\hline 1950 & DB/DB-PR & - & - & - & 133.0 & 124.9 & 117.8 \\
\hline 1955 & $\mathrm{PR}$ & - & 143.9 & 124.3 & 117.8 & 113.7 & 110.2 \\
\hline 1960 & PR & 146.1 & 129.3 & 114.3 & 110.0 & 107.2 & 105.9 \\
\hline 1965 & PR & 130.7 & 115.9 & 103.7 & 101.4 & 100.9 & 99.4 \\
\hline 1970 & PR & 116.5 & 104.5 & 94.8 & 94.3 & 93.6 & 93.1 \\
\hline 1975 & $\mathrm{DC}$ & 114.2 & 101.4 & 92.2 & 92.0 & 91.6 & 92.3 \\
\hline 1980 & $\mathrm{DC}$ & 113.3 & 100.7 & 91.5 & 91.3 & 91.8 & 91.4 \\
\hline 1985 & $\mathrm{DC}$ & 112.4 & 101.0 & 91.8 & 91.5 & 91.0 & 90.5 \\
\hline 1990 & $\mathrm{DC}$ & 112.6 & 100.3 & 91.1 & 90.8 & 90.3 & 90.7 \\
\hline 1995 & $\mathrm{DC}$ & 111.8 & 99.7 & 90.5 & 90.1 & 90.5 & 89.9 \\
\hline 2000 & DC & 111.1 & 99.9 & 90.7 & 90.3 & 89.7 & 89.1 \\
\hline
\end{tabular}


The Geneva Papers on Risk and Insurance-Issues and Practice

664

Table B1 (continued)

\begin{tabular}{|c|c|c|c|c|c|c|c|}
\hline \multicolumn{2}{|c|}{ Cohort/scheme } & \multicolumn{6}{|c|}{ Retirement age } \\
\hline & & 55 & 57 & 60 & 63 & 65 & 67 \\
\hline \multicolumn{8}{|c|}{ Late male white-collar } \\
\hline 1945 & DB/DB-PR & - & - & - & - & - & 120.3 \\
\hline 1950 & PR & - & - & - & 119.5 & 115.7 & 111.6 \\
\hline 1955 & PR & - & 136.5 & 117.3 & 112.0 & 108.6 & 105.8 \\
\hline 1960 & PR & 138.1 & 121.2 & 106.9 & 103.9 & 101.8 & 101.3 \\
\hline 1965 & PR & 122.8 & 108.0 & 96.6 & 95.7 & 96.0 & 95.2 \\
\hline 1970 & PR & 116.5 & 103.7 & 93.5 & 93.3 & 92.8 & 92.3 \\
\hline 1975 & DC & 116.9 & 103.0 & 92.7 & 92.5 & 91.9 & 92.6 \\
\hline 1980 & $\mathrm{DC}$ & 115.9 & 102.3 & 92.0 & 91.7 & 92.2 & 91.7 \\
\hline 1985 & $\mathrm{DC}$ & 115.1 & 102.6 & 92.3 & 92.0 & 91.4 & 90.9 \\
\hline 1990 & $\mathrm{DC}$ & 115.3 & 101.9 & 91.6 & 91.3 & 90.7 & 91.2 \\
\hline 1995 & $\mathrm{DC}$ & 114.5 & 101.3 & 91.0 & 90.6 & 91.0 & 90.4 \\
\hline 2000 & $\mathrm{DC}$ & 113.7 & 101.6 & 91.3 & 90.8 & 90.2 & 89.5 \\
\hline \multicolumn{8}{|c|}{ Male blue-collar } \\
\hline 1945 & DB/DB-PR & - & - & - & - & - & 109.4 \\
\hline 1950 & DB/DB-PR & - & - & - & 121.3 & 112.5 & 104.7 \\
\hline 1955 & DB/DB-PR & - & 151.9 & 128.0 & 114.9 & 107.4 & 100.8 \\
\hline 1960 & PR & 140.8 & 125.4 & 111.2 & 105.8 & 102.4 & 100.4 \\
\hline 1965 & PR & 129.6 & 115.9 & 104.3 & 100.8 & 99.4 & 97.3 \\
\hline 1970 & PR & 118.5 & 107.3 & 98.0 & 96.2 & 94.8 & 93.5 \\
\hline 1975 & $\mathrm{DC}$ & 109.3 & 98.3 & 91.1 & 90.8 & 90.2 & 90.9 \\
\hline 1980 & $\mathrm{DC}$ & 108.2 & 97.4 & 90.2 & 89.9 & 90.4 & 89.8 \\
\hline 1985 & $\mathrm{DC}$ & 107.4 & 97.7 & 90.5 & 90.1 & 89.6 & 89.0 \\
\hline 1990 & $\mathrm{DC}$ & 107.6 & 97.0 & 89.8 & 89.4 & 88.8 & 89.3 \\
\hline 1995 & $\mathrm{DC}$ & 106.8 & 96.4 & 89.2 & 88.8 & 89.1 & 88.5 \\
\hline 2000 & $\mathrm{DC}$ & 106.0 & 96.6 & 89.4 & 89.0 & 88.4 & 87.8 \\
\hline \multicolumn{8}{|c|}{ Female white-collar } \\
\hline 1945 & DB/DB-PR & - & - & - & - & - & 117.9 \\
\hline 1950 & DB/DB-PR & - & - & - & 130.2 & 121.7 & 113.8 \\
\hline 1955 & PR & - & 139.9 & 121.0 & 114.4 & 110.0 & 105.9 \\
\hline 1960 & PR & 141.8 & 126.2 & 111.8 & 107.3 & 104.2 & 102.4 \\
\hline 1965 & PR & 128.6 & 114.6 & 102.8 & 100.4 & 99.6 & 97.8 \\
\hline 1970 & PR & 117.0 & 105.4 & 96.1 & 95.5 & 94.7 & 93.8 \\
\hline 1975 & $\mathrm{DC}$ & 115.4 & 103.1 & 94.3 & 94.1 & 93.5 & 94.1 \\
\hline 1980 & $\mathrm{DC}$ & 114.9 & 102.7 & 94.0 & 93.8 & 94.5 & 94.0 \\
\hline 1985 & $\mathrm{DC}$ & 114.4 & 103.5 & 94.7 & 94.7 & 94.3 & 93.9 \\
\hline 1990 & $\mathrm{DC}$ & 115.1 & 103.2 & 94.6 & 94.6 & 94.2 & 95.0 \\
\hline 1995 & DC & 114.8 & 103.1 & 94.5 & 94.5 & 95.3 & 95.0 \\
\hline 2000 & $\mathrm{DC}$ & 114.6 & 103.9 & 95.3 & 95.5 & 95.3 & 95.1 \\
\hline
\end{tabular}


Table B1 (continued)

\begin{tabular}{|c|c|c|c|c|c|c|c|}
\hline \multicolumn{2}{|c|}{ Cohort/scheme } & \multicolumn{6}{|c|}{ Retirement age } \\
\hline & & 55 & 57 & 60 & 63 & 65 & 67 \\
\hline \multicolumn{8}{|c|}{ Female blue-collar } \\
\hline 1945 & DB/DB-PR & - & - & - & - & - & 92.2 \\
\hline 1950 & DB/DB-PR & - & - & - & 106.2 & 97.2 & 89.1 \\
\hline 1955 & DB/DB-PR & - & 138.1 & 114.4 & 101.4 & 93.9 & 87.1 \\
\hline 1960 & PR & 130.7 & 116.0 & 102.6 & 97.5 & 94.2 & 92.1 \\
\hline 1965 & PR & 122.4 & 109.2 & 98.5 & 95.3 & 94.1 & 91.9 \\
\hline 1970 & PR & 115.0 & 104.4 & 96.0 & 94.6 & 93.4 & 92.1 \\
\hline 1975 & $\mathrm{DC}$ & 111.2 & 100.1 & 93.1 & 92.7 & 92.1 & 92.5 \\
\hline 1980 & $\mathrm{DC}$ & 110.7 & 99.9 & 92.9 & 92.6 & 93.1 & 92.5 \\
\hline 1985 & $\mathrm{DC}$ & 110.2 & 100.5 & 93.6 & 93.4 & 92.9 & 92.3 \\
\hline 1990 & $\mathrm{DC}$ & 110.8 & 100.3 & 93.4 & 93.3 & 92.8 & 93.4 \\
\hline 1995 & $\mathrm{DC}$ & 110.5 & 100.2 & 93.3 & 93.3 & 93.9 & 93.5 \\
\hline 2000 & $\mathrm{DC}$ & 110.3 & 101.0 & 94.2 & 94.3 & 93.9 & 93.6 \\
\hline \multicolumn{8}{|c|}{ Scenario: $A B$} \\
\hline \multirow{2}{*}{\multicolumn{2}{|c|}{ Cohort/scheme }} & \multicolumn{6}{|c|}{ Retirement age } \\
\hline & & 55 & 57 & 60 & 63 & 65 & 67 \\
\hline \multicolumn{8}{|c|}{ Male white-collar } \\
\hline 1945 & DB/DB-PR & - & - & - & - & - & 125.8 \\
\hline 1950 & DB/DB-PR & - & - & - & 132.6 & 124.0 & 116.5 \\
\hline 1955 & $\mathrm{PR}$ & - & 136.7 & 119.2 & 112.6 & 108.8 & 105.7 \\
\hline 1960 & PR & 138.0 & 123.1 & 108.9 & 104.6 & 102.2 & 100.3 \\
\hline 1965 & PR & 122.4 & 109.4 & 98.1 & 96.0 & 94.9 & 93.9 \\
\hline 1970 & PR & 108.1 & 96.9 & 88.2 & 87.9 & 87.9 & 87.9 \\
\hline 1975 & $\mathrm{DC}$ & 105.2 & 94.4 & 86.1 & 86.2 & 86.3 & 86.5 \\
\hline 1980 & $\mathrm{DC}$ & 105.0 & 94.3 & 86.0 & 86.0 & 86.1 & 86.2 \\
\hline 1985 & $\mathrm{DC}$ & 104.8 & 94.2 & 85.8 & 85.8 & 85.9 & 85.9 \\
\hline 1990 & $\mathrm{DC}$ & 104.6 & 94.1 & 85.7 & 85.7 & 85.7 & 85.7 \\
\hline 1995 & $\mathrm{DC}$ & 104.4 & 93.9 & 85.5 & 85.5 & 85.4 & 85.4 \\
\hline 2000 & $\mathrm{DC}$ & 104.2 & 93.8 & 85.3 & 85.2 & 85.1 & 85.1 \\
\hline \multicolumn{8}{|c|}{ Late male white-collar } \\
\hline 1945 & DB/DB-PR & - & - & - & - & - & 119.9 \\
\hline 1950 & PR & - & - & - & 115.3 & 110.8 & 107.0 \\
\hline 1955 & PR & - & 128.6 & 111.8 & 106.4 & 103.4 & 101.0 \\
\hline 1960 & PR & 129.2 & 114.4 & 101.0 & 98.1 & 96.6 & 95.3 \\
\hline 1965 & PR & 113.6 & 101.0 & 90.6 & 89.9 & 89.6 & 89.4 \\
\hline 1970 & $\mathrm{PR}$ & 107.8 & 96.0 & 86.7 & 86.8 & 86.9 & 87.1 \\
\hline 1975 & $\mathrm{DC}$ & 107.7 & 95.9 & 86.6 & 86.6 & 86.7 & 86.8 \\
\hline 1980 & $\mathrm{DC}$ & 107.5 & 95.8 & 86.4 & 86.4 & 86.5 & 86.6 \\
\hline 1985 & $\mathrm{DC}$ & 107.3 & 95.7 & 86.3 & 86.3 & 86.3 & 86.3 \\
\hline 1990 & $\mathrm{DC}$ & 107.1 & 95.6 & 86.2 & 86.1 & 86.1 & 86.1 \\
\hline 1995 & $\mathrm{DC}$ & 106.9 & 95.5 & 86.0 & 86.0 & 85.9 & 85.8 \\
\hline 2000 & $\mathrm{DC}$ & 106.8 & 95.4 & 85.9 & 85.7 & 85.6 & 85.5 \\
\hline
\end{tabular}


The Geneva Papers on Risk and Insurance-Issues and Practice

666

Table B1 (continued)

\begin{tabular}{|c|c|c|c|c|c|c|c|}
\hline \multicolumn{2}{|c|}{ Cohort/scheme } & \multicolumn{6}{|c|}{ Retirement age } \\
\hline & & 55 & 57 & 60 & 63 & 65 & 67 \\
\hline \multicolumn{8}{|c|}{ Male blue-collar } \\
\hline 1945 & DB/DB-PR & - & - & - & - & - & 109.1 \\
\hline 1950 & DB/DB-PR & - & - & - & 121.0 & 111.8 & 103.8 \\
\hline 1955 & DB/DB-PR & - & 150.8 & 127.2 & 113.7 & 106.0 & 99.4 \\
\hline 1960 & PR & 133.9 & 120.1 & 106.5 & 101.1 & 98.1 & 95.5 \\
\hline 1965 & PR & 122.4 & 110.3 & 99.4 & 96.0 & 94.1 & 92.4 \\
\hline 1970 & PR & 111.0 & 100.5 & 92.0 & 90.4 & 89.5 & 88.7 \\
\hline 1975 & DC & 100.7 & 91.5 & 85.1 & 85.1 & 85.1 & 85.2 \\
\hline 1980 & $\mathrm{DC}$ & 100.3 & 91.2 & 84.8 & 84.8 & 84.7 & 84.8 \\
\hline 1985 & $\mathrm{DC}$ & 100.1 & 91.1 & 84.6 & 84.5 & 84.5 & 84.5 \\
\hline 1990 & $\mathrm{DC}$ & 99.9 & 91.0 & 84.4 & 84.4 & 84.3 & 84.3 \\
\hline 1995 & $\mathrm{DC}$ & 99.7 & 90.8 & 84.3 & 84.2 & 84.1 & 84.1 \\
\hline 2000 & DC & 99.5 & 90.7 & 84.1 & 84.0 & 83.9 & 83.8 \\
\hline \multicolumn{8}{|c|}{ Female white-collar } \\
\hline 1945 & DB/DB-PR & - & - & - & - & - & 117.5 \\
\hline 1950 & DB/DB-PR & - & - & - & 129.6 & 120.5 & 112.2 \\
\hline 1955 & $\mathrm{PR}$ & - & 131.1 & 114.3 & 107.3 & 103.1 & 99.2 \\
\hline 1960 & PR & 131.3 & 117.8 & 104.1 & 99.4 & 96.6 & 93.9 \\
\hline 1965 & PR & 117.2 & 105.3 & 94.4 & 91.8 & 90.2 & 88.7 \\
\hline 1970 & PR & 104.7 & 94.3 & 85.7 & 85.0 & 84.5 & 84.0 \\
\hline 1975 & $\mathrm{DC}$ & 102.1 & 92.1 & 84.0 & 83.7 & 83.4 & 83.2 \\
\hline 1980 & $\mathrm{DC}$ & 101.9 & 92.0 & 84.0 & 83.7 & 83.5 & 83.2 \\
\hline 1985 & $\mathrm{DC}$ & 101.7 & 92.0 & 83.9 & 83.6 & 83.4 & 83.2 \\
\hline 1990 & $\mathrm{DC}$ & 101.5 & 91.9 & 83.9 & 83.6 & 83.4 & 83.2 \\
\hline 1995 & $\mathrm{DC}$ & 101.2 & 91.8 & 83.8 & 83.5 & 83.3 & 83.1 \\
\hline 2000 & $\mathrm{DC}$ & 101.0 & 91.6 & 83.7 & 83.4 & 83.3 & 83.1 \\
\hline \multicolumn{8}{|c|}{ Female blue-collar } \\
\hline 1945 & DB/DB-PR & - & - & - & - & - & 92.0 \\
\hline 1950 & DB/DB-PR & - & - & - & 105.8 & 96.3 & 87.9 \\
\hline 1955 & DB/DB-PR & - & 136.7 & 113.4 & 99.7 & 91.9 & 84.9 \\
\hline 1960 & $\mathrm{PR}$ & 121.5 & 108.6 & 95.7 & 90.5 & 87.4 & 84.5 \\
\hline 1965 & PR & 112.1 & 100.9 & 90.7 & 87.5 & 85.5 & 83.6 \\
\hline 1970 & PR & 103.8 & 94.1 & 86.3 & 84.8 & 83.9 & 82.9 \\
\hline 1975 & DC & 98.3 & 89.5 & 83.0 & 82.5 & 82.2 & 81.8 \\
\hline 1980 & $\mathrm{DC}$ & 98.2 & 89.5 & 83.0 & 82.6 & 82.2 & 81.9 \\
\hline 1985 & $\mathrm{DC}$ & 97.9 & 89.3 & 82.9 & 82.5 & 82.2 & 81.8 \\
\hline 1990 & $\mathrm{DC}$ & 97.7 & 89.3 & 82.9 & 82.5 & 82.2 & 81.8 \\
\hline 1995 & DC & 97.5 & 89.2 & 82.8 & 82.4 & 82.1 & 81.8 \\
\hline 2000 & $\mathrm{DC}$ & 97.3 & 89.0 & 82.7 & 82.3 & 82.0 & 81.8 \\
\hline
\end{tabular}

Notes: percentage points; in italics: only if eligible for disability; - : retirement year is <2012; scenario: $B_{2011}$ : current pension rules; $B_{1995}: 1995$ pension rules; $A B$ : quasi-actuarial benchmark; scheme: $\mathrm{DB}=$ defined benefit, DB$\mathrm{PR}=$ extended pro-rata, $\mathrm{PR}=$ pro-rata, $\mathrm{DC}=$ notional defined contribution; $g_{f}=0.015, r=0.02$. 
Table B2 TAX by selected cohort and retirement age-alternative normative scenarios and types of worker

\begin{tabular}{|c|c|c|c|c|c|c|c|}
\hline \multicolumn{2}{|c|}{ Cohort/scheme } & \multicolumn{6}{|c|}{ Retirement age } \\
\hline & & 55 & 57 & 60 & 63 & 65 & 67 \\
\hline \multicolumn{8}{|c|}{ Male white-collar } \\
\hline 1945 & DB/DB-PR & - & - & - & - & - & 88.2 \\
\hline 1950 & DB/DB-PR & - & - & - & 50.2 & 88.5 & 88.7 \\
\hline 1955 & PR & - & 55.6 & 19.5 & 20.2 & 25.1 & 25.5 \\
\hline 1960 & PR & 72.4 & 48.6 & 16.8 & 16.9 & 17.1 & 17.4 \\
\hline 1965 & PR & 67.9 & 43.7 & 9.2 & 9.2 & 12.5 & 13.3 \\
\hline 1970 & PR & 64.9 & 37.0 & 4.9 & 5.2 & 5.3 & 5.5 \\
\hline 1975 & $\mathrm{DC}$ & 63.0 & 36.5 & 2.6 & 2.6 & 5.6 & 5.8 \\
\hline 1980 & $\mathrm{DC}$ & 62.8 & 35.9 & 3.9 & 4.0 & 4.0 & 4.1 \\
\hline 1985 & $\mathrm{DC}$ & 61.7 & 36.4 & 2.8 & 2.7 & 5.4 & 5.4 \\
\hline 1990 & $\mathrm{DC}$ & 61.5 & 35.9 & 4.0 & 4.0 & 3.9 & 3.8 \\
\hline 1995 & $\mathrm{DC}$ & 60.5 & 36.4 & 2.9 & 2.7 & 5.0 & 5.0 \\
\hline 2000 & $\mathrm{DC}$ & 60.3 & 35.9 & 4.0 & 3.8 & 3.7 & 3.5 \\
\hline \multicolumn{8}{|c|}{ Late male white-collar } \\
\hline 1945 & DB/DB-PR & - & - & - & - & - & 54.9 \\
\hline 1950 & PR & - & - & - & 23.3 & 23.2 & 23.2 \\
\hline 1955 & PR & - & 50.6 & 14.7 & 15.0 & 19.9 & 20.3 \\
\hline 1960 & PR & 67.2 & 43.8 & 11.7 & 11.9 & 12.1 & 12.3 \\
\hline 1965 & PR & 63.0 & 38.7 & 4.5 & 4.5 & 7.9 & 8.2 \\
\hline 1970 & PR & 61.7 & 35.8 & 3.6 & 3.8 & 3.9 & 4.0 \\
\hline 1975 & $\mathrm{DC}$ & 60.6 & 36.3 & 2.4 & 2.3 & 5.2 & 5.4 \\
\hline 1980 & $\mathrm{DC}$ & 60.4 & 35.7 & 3.7 & 3.7 & 3.8 & 3.8 \\
\hline 1985 & $\mathrm{DC}$ & 59.4 & 36.3 & 2.6 & 2.4 & 5.0 & 5.1 \\
\hline 1990 & $\mathrm{DC}$ & 59.2 & 35.8 & 3.8 & 3.7 & 3.7 & 3.6 \\
\hline 1995 & $\mathrm{DC}$ & 58.3 & 36.2 & 2.8 & 2.5 & 4.7 & 4.7 \\
\hline 2000 & $\mathrm{DC}$ & 58.1 & 35.8 & 3.7 & 3.6 & 3.5 & 3.3 \\
\hline \multicolumn{8}{|c|}{ Male blue-collar } \\
\hline 1945 & DB/DB-PR & - & - & - & - & - & 111.9 \\
\hline 1950 & DB/DB-PR & - & - & - & 111.2 & 111.5 & 112.0 \\
\hline 1955 & DB/DB-PR & - & 108.6 & 110.4 & 111.3 & 111.6 & 112.1 \\
\hline 1960 & PR & 90.0 & 65.0 & 30.6 & 31.4 & 32.1 & 32.9 \\
\hline 1965 & PR & 83.8 & 56.8 & 20.3 & 20.9 & 24.9 & 25.8 \\
\hline 1970 & PR & 79.3 & 47.1 & 13.0 & 13.8 & 14.3 & 14.9 \\
\hline 1975 & DC & 73.9 & 39.8 & 3.5 & 3.8 & 7.7 & 8.3 \\
\hline 1980 & $\mathrm{DC}$ & 73.7 & 39.0 & 5.0 & 5.4 & 5.7 & 6.0 \\
\hline 1985 & $\mathrm{DC}$ & 72.2 & 39.7 & 3.6 & 3.8 & 7.2 & 7.6 \\
\hline 1990 & $\mathrm{DC}$ & 72.0 & 39.0 & 5.0 & 5.3 & 5.4 & 5.6 \\
\hline 1995 & $\mathrm{DC}$ & 70.6 & 39.6 & 3.8 & 3.7 & 6.9 & 7.1 \\
\hline 2000 & $\mathrm{DC}$ & 70.4 & 39.0 & 5.0 & 5.2 & 5.2 & 5.2 \\
\hline
\end{tabular}


The Geneva Papers on Risk and Insurance-Issues and Practice 668

Table B2 (continued)

\begin{tabular}{|c|c|c|c|c|c|c|c|}
\hline \multicolumn{2}{|c|}{ Cohort/scheme } & \multicolumn{6}{|c|}{ Retirement age } \\
\hline & & 55 & 57 & 60 & 63 & 65 & 67 \\
\hline \multicolumn{8}{|c|}{ Female white-collar } \\
\hline 1945 & DB/DB-PR & - & - & - & - & - & 94.7 \\
\hline 1950 & DB/DB-PR & - & - & - & 48.5 & 92.8 & 94.2 \\
\hline 1955 & PR & - & 54.6 & 19.1 & 18.7 & 24.1 & 24.7 \\
\hline 1960 & PR & 69.9 & 47.8 & 15.0 & 15.1 & 15.2 & 15.3 \\
\hline 1965 & PR & 67.3 & 42.8 & 6.9 & 6.5 & 9.8 & 9.7 \\
\hline 1970 & PR & 65.7 & 36.0 & 1.9 & 1.4 & 1.0 & 0.5 \\
\hline 1975 & DC & 63.9 & 35.3 & -1.0 & -1.9 & 0.9 & 0.5 \\
\hline 1980 & $\mathrm{DC}$ & 63.6 & 34.5 & 0.2 & -0.6 & -1.3 & -2.1 \\
\hline 1985 & $\mathrm{DC}$ & 62.4 & 35.0 & -1.4 & -2.6 & -0.1 & -0.9 \\
\hline 1990 & $\mathrm{DC}$ & 62.0 & 34.2 & -0.4 & -1.4 & -2.3 & -3.4 \\
\hline 1995 & $\mathrm{DC}$ & 60.9 & 34.6 & -2.0 & -3.4 & -1.3 & -2.3 \\
\hline 2000 & $\mathrm{DC}$ & 60.6 & 33.8 & -1.1 & -2.4 & -3.5 & -4.8 \\
\hline \multicolumn{8}{|c|}{ Female blue-collar } \\
\hline 1945 & DB/DB-PR & - & - & - & - & - & 123.0 \\
\hline 1950 & DB/DB-PR & - & - & - & 123.6 & 123.6 & 123.5 \\
\hline 1955 & DB/DB-PR & - & 116.4 & 70.4 & 124.1 & 124.1 & 124.0 \\
\hline 1960 & PR & 92.9 & 65.2 & 28.4 & 28.4 & 28.5 & 28.5 \\
\hline 1965 & PR & 86.0 & 55.4 & 16.2 & 15.8 & 19.7 & 19.8 \\
\hline 1970 & PR & 81.1 & 43.8 & 7.0 & 6.9 & 6.7 & 6.3 \\
\hline 1975 & $\mathrm{DC}$ & 77.0 & 38.7 & -0.9 & -1.8 & 1.8 & 1.4 \\
\hline 1980 & $\mathrm{DC}$ & 76.8 & 37.6 & 0.5 & -0.3 & -1.0 & -1.9 \\
\hline 1985 & $\mathrm{DC}$ & 75.1 & 38.3 & -1.5 & -2.8 & 0.3 & -0.6 \\
\hline 1990 & $\mathrm{DC}$ & 74.8 & 37.3 & -0.3 & -1.4 & -2.5 & -3.8 \\
\hline 1995 & $\mathrm{DC}$ & 73.3 & 37.8 & -2.2 & -3.8 & -1.3 & -2.6 \\
\hline 2000 & $\mathrm{DC}$ & 72.9 & 36.8 & -1.2 & -2.7 & -4.1 & -5.8 \\
\hline \multicolumn{8}{|c|}{ Scenario: $B_{2011}$} \\
\hline \multirow{2}{*}{\multicolumn{2}{|c|}{ Cohort/scheme }} & \multicolumn{6}{|c|}{ Retirement age } \\
\hline & & 55 & 57 & 60 & 63 & 65 & 67 \\
\hline \multicolumn{8}{|c|}{ Male white-collar } \\
\hline 1945 & DB/DB-PR & - & - & - & - & - & 57.6 \\
\hline 1950 & DB/DB-PR & - & - & - & 49.2 & 52.6 & 50.6 \\
\hline 1955 & PR & - & 79.0 & 31.3 & 35.5 & 24.8 & 26.1 \\
\hline 1960 & PR & 82.4 & 49.5 & 16.5 & 17.5 & 18.7 & 35.2 \\
\hline 1965 & PR & 68.0 & 43.9 & 10.6 & 11.6 & 27.7 & 13.6 \\
\hline 1970 & PR & 64.3 & 50.0 & 17.8 & 20.8 & 6.6 & 7.8 \\
\hline 1975 & $\mathrm{DC}$ & 75.5 & 36.6 & 3.6 & 4.6 & 5.6 & 23.4 \\
\hline 1980 & $\mathrm{DC}$ & 62.4 & 36.7 & 3.9 & 4.8 & 20.4 & 5.9 \\
\hline 1985 & $\mathrm{DC}$ & 61.7 & 47.4 & 15.3 & 17.8 & 5.1 & 6.0 \\
\hline 1990 & $\mathrm{DC}$ & 71.9 & 36.5 & 3.8 & 4.5 & 5.2 & 20.7 \\
\hline 1995 & $\mathrm{DC}$ & 60.6 & 36.6 & 4.0 & 4.6 & 18.2 & 5.2 \\
\hline 2000 & $\mathrm{DC}$ & 59.9 & 46.1 & 14.0 & 16.0 & 4.6 & 5.2 \\
\hline
\end{tabular}


Table B2 (continued)

\begin{tabular}{|c|c|c|c|c|c|c|c|}
\hline \multicolumn{2}{|c|}{ Cohort/scheme } & \multicolumn{6}{|c|}{ Retirement age } \\
\hline & & 55 & 57 & 60 & 63 & 65 & 67 \\
\hline \multicolumn{8}{|c|}{ Late male white-collar } \\
\hline 1945 & DB/DB-PR & - & - & - & - & - & 52.2 \\
\hline 1950 & PR & - & - & - & 25.6 & 37.3 & 27.1 \\
\hline 1955 & PR & - & 74.0 & 26.5 & 30.3 & 19.6 & 20.9 \\
\hline 1960 & PR & 77.2 & 44.7 & 11.5 & 12.5 & 13.6 & 30.2 \\
\hline 1965 & PR & 63.1 & 38.9 & 5.9 & 6.9 & 23.1 & 8.5 \\
\hline 1970 & PR & 61.2 & 47.9 & 15.6 & 18.4 & 5.1 & 6.3 \\
\hline 1975 & DC & 72.1 & 36.4 & 3.4 & 4.3 & 5.2 & 21.8 \\
\hline 1980 & DC & 60.1 & 36.5 & 3.7 & 4.5 & 18.9 & 5.6 \\
\hline 1985 & DC & 59.4 & 46.3 & 14.1 & 16.5 & 4.8 & 5.6 \\
\hline 1990 & DC & 68.7 & 36.3 & 3.5 & 4.2 & 4.9 & 19.3 \\
\hline 1995 & DC & 58.3 & 36.4 & 3.8 & 4.3 & 16.9 & 4.9 \\
\hline 2000 & DC & 57.8 & 45.0 & 13.0 & 14.8 & 4.3 & 4.9 \\
\hline \multicolumn{8}{|c|}{ Male blue-collar } \\
\hline 1945 & DB/DB-PR & - & - & - & - & - & 90.4 \\
\hline 1950 & DB/DB-PR & - & - & - & 78.3 & 81.6 & 79.9 \\
\hline 1955 & DB/DB-PR & - & 108.0 & 70.4 & 73.6 & 70.3 & 71.7 \\
\hline 1960 & PR & 100.8 & 66.0 & 30.3 & 32.1 & 33.8 & 54.9 \\
\hline 1965 & PR & 83.9 & 57.0 & 21.8 & 23.5 & 44.2 & 26.2 \\
\hline 1970 & PR & 78.6 & 62.5 & 28.9 & 33.6 & 15.8 & 17.6 \\
\hline 1975 & DC & 90.0 & 39.9 & 4.7 & 6.2 & 7.7 & 33.7 \\
\hline 1980 & DC & 73.2 & 40.0 & 5.0 & 6.4 & 28.7 & 8.3 \\
\hline 1985 & DC & 72.2 & 54.0 & 20.6 & 24.6 & 6.9 & 8.3 \\
\hline 1990 & DC & 85.3 & 39.8 & 4.8 & 5.9 & 7.0 & 29.9 \\
\hline 1995 & DC & 70.7 & 39.9 & 5.0 & 6.1 & 25.9 & 7.5 \\
\hline 2000 & DC & 69.9 & 52.3 & 18.9 & 22.5 & 6.5 & 7.6 \\
\hline \multicolumn{8}{|c|}{ Female white-collar } \\
\hline 1945 & DB/DB-PR & - & - & - & - & - & 63.1 \\
\hline 1950 & DB/DB-PR & - & - & - & 50.5 & 55.0 & 53.8 \\
\hline 1955 & PR & - & 79.0 & 31.6 & 35.2 & 23.8 & 25.3 \\
\hline 1960 & PR & 80.4 & 48.9 & 14.7 & 15.8 & 16.9 & 35.4 \\
\hline 1965 & PR & 67.4 & 43.0 & 8.4 & 9.2 & 27.1 & 10.1 \\
\hline 1970 & PR & 65.2 & 50.5 & 16.5 & 19.5 & 2.4 & 3.2 \\
\hline 1975 & DC & 77.8 & 35.4 & 0.1 & 0.4 & 0.9 & 21.4 \\
\hline 1980 & DC & 63.2 & 35.4 & 0.2 & 0.3 & 18.1 & 0.1 \\
\hline 1985 & DC & 62.4 & 47.4 & 13.1 & 15.3 & -0.5 & -0.2 \\
\hline 1990 & DC & 73.7 & 34.9 & -0.6 & -0.9 & -0.7 & 17.3 \\
\hline 1995 & DC & 61.0 & 34.9 & -0.7 & -1.0 & 14.7 & -2.0 \\
\hline 2000 & DC & 60.2 & 45.5 & 10.8 & 12.5 & -2.2 & -2.4 \\
\hline
\end{tabular}


The Geneva Papers on Risk and Insurance-Issues and Practice

670

Table B2 (continued)

\begin{tabular}{|c|c|c|c|c|c|c|c|}
\hline \multicolumn{2}{|c|}{ Cohort/scheme } & \multicolumn{6}{|c|}{ Retirement age } \\
\hline & & 55 & 57 & 60 & 63 & 65 & 67 \\
\hline \multicolumn{8}{|c|}{ Female blue-collar } \\
\hline 1945 & DB/DB-PR & - & - & - & - & - & 97.5 \\
\hline 1950 & DB/DB-PR & - & - & - & 85.1 & 88.0 & 85.4 \\
\hline 1955 & DB/DB-PR & - & 116.4 & 76.4 & 79.0 & 74.8 & 75.5 \\
\hline 1960 & PR & 104.7 & 66.3 & 28.1 & 29.1 & 30.4 & 54.1 \\
\hline 1965 & PR & 86.1 & 55.7 & 17.8 & 18.8 & 42.3 & 20.2 \\
\hline 1970 & PR & 80.3 & 61.6 & 25.8 & 30.5 & 8.4 & 9.6 \\
\hline 1975 & $\mathrm{DC}$ & 94.8 & 38.8 & 0.5 & 1.0 & 1.8 & 31.7 \\
\hline 1980 & DC & 76.2 & 38.8 & 0.5 & 0.8 & 26.3 & 0.9 \\
\hline 1985 & $\mathrm{DC}$ & 75.1 & 54.5 & 18.2 & 21.8 & -0.1 & 0.3 \\
\hline 1990 & $\mathrm{DC}$ & 89.7 & 38.2 & -0.6 & -0.7 & -0.5 & 25.8 \\
\hline 1995 & $\mathrm{DC}$ & 73.4 & 38.1 & -0.7 & -1.0 & 21.6 & -2.1 \\
\hline 2000 & DC & 72.4 & 52.1 & 15.1 & 18.0 & -2.5 & -2.8 \\
\hline
\end{tabular}

Scenario: $A B$

Cohort/scheme

Retirement age

\begin{tabular}{llllll}
\hline 55 & 57 & 60 & 63 & 65 & 67
\end{tabular}

\begin{tabular}{|c|c|c|c|c|c|c|c|}
\hline \multicolumn{8}{|c|}{ Male white-collar } \\
\hline 1945 & DB/DB-PR & - & - & - & - & - & 58.5 \\
\hline 1950 & DB/DB-PR & - & - & - & 52.1 & 53.2 & 54.1 \\
\hline 1955 & PR & - & 58.1 & 26.5 & 29.2 & 30.2 & 31.5 \\
\hline 1960 & PR & 69.7 & 52.0 & 21.6 & 22.9 & 24.0 & 25.2 \\
\hline 1965 & PR & 65.9 & 46.4 & 15.5 & 16.8 & 17.9 & 19.5 \\
\hline 1970 & PR & 62.2 & 40.6 & 10.0 & 11.3 & 12.3 & 13.4 \\
\hline 1975 & $\mathrm{DC}$ & 61.0 & 39.3 & 8.7 & 9.9 & 10.8 & 11.8 \\
\hline 1980 & DC & 60.5 & 39.1 & 8.5 & 9.6 & 10.4 & 11.4 \\
\hline 1985 & DC & 59.9 & 38.9 & 8.3 & 9.3 & 10.1 & 10.8 \\
\hline 1990 & DC & 59.4 & 38.8 & 8.1 & 9.0 & 9.6 & 10.2 \\
\hline 1995 & DC & 58.9 & 38.7 & 8.0 & 8.6 & 9.1 & 9.7 \\
\hline 2000 & $\mathrm{DC}$ & 58.4 & 38.5 & 7.6 & 8.2 & 8.6 & 9.1 \\
\hline \multicolumn{8}{|c|}{ Late male white-collar } \\
\hline 1945 & DB/DB-PR & - & - & - & - & - & 53.2 \\
\hline 1950 & PR & - & - & - & 30.3 & 31.3 & 32.5 \\
\hline 1955 & PR & - & 53.1 & 21.8 & 24.0 & 25.0 & 26.2 \\
\hline 1960 & PR & 64.5 & 47.1 & 16.6 & 17.9 & 18.9 & 20.1 \\
\hline 1965 & PR & 61.1 & 41.5 & 10.8 & 12.1 & 13.2 & 14.4 \\
\hline 1970 & PR & 59.3 & 39.1 & 8.4 & 9.6 & 10.6 & 11.7 \\
\hline 1975 & $\mathrm{DC}$ & 58.8 & 38.9 & 8.2 & 9.3 & 10.2 & 11.2 \\
\hline 1980 & $\mathrm{DC}$ & 58.3 & 38.7 & 8.0 & 9.1 & 9.9 & 10.8 \\
\hline 1985 & DC & 57.8 & 38.5 & 7.9 & 8.8 & 9.5 & 10.3 \\
\hline 1990 & $\mathrm{DC}$ & 57.3 & 38.4 & 7.7 & 8.6 & 9.1 & 9.7 \\
\hline 1995 & DC & 56.8 & 38.3 & 7.6 & 8.2 & 8.6 & 9.1 \\
\hline 2000 & DC & 56.4 & 38.2 & 7.2 & 7.7 & 8.2 & 8.6 \\
\hline
\end{tabular}


Table B2 (continued)

\begin{tabular}{|c|c|c|c|c|c|c|c|}
\hline \multicolumn{8}{|c|}{ Scenario: $A B$} \\
\hline \multicolumn{2}{|c|}{ Cohort/scheme } & \multicolumn{6}{|c|}{ Retirement age } \\
\hline & & 55 & 57 & 60 & 63 & 65 & 67 \\
\hline \multicolumn{8}{|c|}{ Male blue-collar } \\
\hline 1945 & DB/DB-PR & - & - & - & - & - & 91.3 \\
\hline 1950 & DB/DB-PR & - & - & - & 81.2 & 82.2 & 83.5 \\
\hline 1955 & DB/DB-PR & - & 103.4 & 71.4 & 73.0 & 74.1 & 75.5 \\
\hline 1960 & PR & 86.6 & 68.5 & 35.8 & 38.0 & 39.8 & 41.7 \\
\hline 1965 & PR & 81.4 & 59.7 & 27.2 & 29.4 & 31.2 & 33.1 \\
\hline 1970 & PR & 75.9 & 51.0 & 18.7 & 20.8 & 22.5 & 24.4 \\
\hline 1975 & $\mathrm{DC}$ & 71.2 & 43.2 & 10.8 & 12.7 & 14.3 & 16.0 \\
\hline 1980 & $\mathrm{DC}$ & 70.4 & 43.0 & 10.5 & 12.2 & 13.7 & 15.3 \\
\hline 1985 & $\mathrm{DC}$ & 69.7 & 42.8 & 10.2 & 11.8 & 13.2 & 14.6 \\
\hline 1990 & $\mathrm{DC}$ & 69.1 & 42.6 & 10.0 & 11.5 & 12.7 & 14.1 \\
\hline 1995 & $\mathrm{DC}$ & 68.4 & 42.4 & 9.8 & 11.2 & 12.3 & 13.5 \\
\hline 2000 & $\mathrm{DC}$ & 67.8 & 42.3 & 9.6 & 10.9 & 12.0 & 13.1 \\
\hline \multicolumn{8}{|c|}{ Female white-collar } \\
\hline 1945 & DB/DB-PR & - & - & - & - & - & 65.3 \\
\hline 1950 & DB/DB-PR & - & - & - & 54.7 & 57.0 & 58.9 \\
\hline 1955 & PR & - & 57.8 & 28.3 & 30.2 & 31.7 & 33.4 \\
\hline 1960 & PR & 66.6 & 52.3 & 22.3 & 24.0 & 25.2 & 26.7 \\
\hline 1965 & PR & 64.5 & 47.0 & 16.3 & 17.7 & 18.9 & 20.1 \\
\hline 1970 & PR & 62.0 & 41.5 & 10.5 & 11.7 & 12.6 & 13.6 \\
\hline 1975 & $\mathrm{DC}$ & 60.8 & 40.2 & 9.2 & 10.2 & 11.0 & 11.9 \\
\hline 1980 & $\mathrm{DC}$ & 60.1 & 40.1 & 9.0 & 9.9 & 10.6 & 11.4 \\
\hline 1985 & $\mathrm{DC}$ & 59.4 & 39.9 & 8.8 & 9.6 & 10.3 & 10.9 \\
\hline 1990 & $\mathrm{DC}$ & 58.7 & 39.8 & 8.7 & 9.4 & 10.0 & 10.5 \\
\hline 1995 & $\mathrm{DC}$ & 58.0 & 39.7 & 8.6 & 9.2 & 9.7 & 10.2 \\
\hline 2000 & $\mathrm{DC}$ & 57.3 & 39.6 & 8.5 & 9.0 & 9.5 & 9.9 \\
\hline \multicolumn{8}{|c|}{ Female blue-collar } \\
\hline 1945 & DB/DB-PR & - & - & - & - & - & 99.6 \\
\hline 1950 & DB/DB-PR & - & - & - & 89.3 & 89.8 & 90.5 \\
\hline 1955 & DB/DB-PR & - & 111.6 & 78.7 & 79.8 & 80.5 & 81.3 \\
\hline 1960 & PR & 88.3 & 70.0 & 36.5 & 38.4 & 39.9 & 41.7 \\
\hline 1965 & PR & 82.2 & 60.1 & 26.7 & 28.7 & 30.3 & 32.1 \\
\hline 1970 & PR & 76.0 & 50.2 & 17.0 & 19.0 & 20.6 & 22.4 \\
\hline 1975 & $\mathrm{DC}$ & 72.5 & 44.8 & 11.3 & 13.1 & 14.5 & 16.0 \\
\hline 1980 & $\mathrm{DC}$ & 71.6 & 44.6 & 11.1 & 12.7 & 13.9 & 15.3 \\
\hline 1985 & $\mathrm{DC}$ & 70.7 & 44.4 & 10.9 & 12.3 & 13.4 & 14.6 \\
\hline 1990 & $\mathrm{DC}$ & 69.8 & 44.2 & 10.6 & 11.9 & 12.9 & 14.0 \\
\hline 1995 & $\mathrm{DC}$ & 68.9 & 44.0 & 10.4 & 11.6 & 12.5 & 13.5 \\
\hline 2000 & $\mathrm{DC}$ & 68.0 & 43.9 & 10.3 & 11.3 & 12.1 & 13.0 \\
\hline
\end{tabular}

Notes: percentage points; in italics: only if eligible for disability; - : retirement year is <2012; scenario: $B_{2011}$ : current pension rules; $B_{1995}: 1995$ pension rules; $A B$ : quasi-actuarial benchmark; scheme: $\mathrm{DB}=$ defined benefit, DB$\mathrm{PR}=$ extended pro-rata, $\mathrm{PR}=$ pro-rata, $\mathrm{DC}=$ notional defined contribution; $g_{f}=0.015, r=0.02$. 


\section{Appendix C}

\section{Mortality forecasts: Methodology}

The first step needed for the projection consists in converting the indication of the experts on the human being limit characteristics ${ }^{34}$ into an appropriate survival function. Following previous studies, ${ }^{62}$ we model the trend in endogenous mortality $q_{\text {end }}(x)$ by means of a Weibull model. This generates a process of mortality of an initial closed contingent of individuals of the same age according to the following survival function:

$$
\ell(x)=\exp \left[-\left(\frac{x-a}{m}\right)^{b}\right] \quad, \quad x \geqslant a ; a \geqslant 0 ; b, m>0 .
$$

The derivative of (C.1) provides the corresponding function of deaths that corresponds to the Weibull statistical distribution

$$
f(x)= \begin{cases}\frac{b}{m}\left(\frac{x-a}{m}\right)^{b-1} \exp \left[-\left(\frac{x-a}{m}\right)^{b}\right], & x \geqslant a ; a \geqslant 0 ; b, m>0 \\ 0 & \text { otherwise }\end{cases}
$$

where we interpret $f(x) d x$ as the fraction of components of an initial contingent that are eliminated at age $[x, x+d x)$. Parameters $a, b, m$ have been set consistently with the envisaged characteristics of the limit scenario, which are: $e_{0}=109.4$ years, life span about 125 years, minimum life equal to 70 years, median age at death equal to 109 years. ${ }^{63}$ The Weibull distribution is widely used in life data analysis due to its versatility; ${ }^{64}$ in particular the threeparameters type permits fairly effective control of important features of the survival reference scenario, such as life expectancy at birth, the Lexis point, the median age at death and also the threshold below which mortality is considered avoidable. They are all functions of the parameters in Eq. (C.1). ${ }^{65}$ Specifically, we set $a=70, b=7.5$ and $m=45$.

We then build the limit probabilities of dying due to exogenous or accidental causes $q_{\text {eso }}(x)$, that is, accidents, traumas, etc. We first select a group of developed countries for which detailed and updated statistic on causes of death are available. ${ }^{66}$ Focusing on accidental causes of death, we then construct an empirical function of minimum mortality by age (Nizard and Vallin, 1970): that is, for each age, we select the minimum level of mortality observed in these countries. Finally, we fit a fifth degree polynomial, which provides the analytical form of $q_{e s o}(x)$, to the empirical function obtained in this way.

\footnotetext{
${ }^{62}$ See e.g. Duchêne and Wunsch (1993); Maccheroni (1998).

${ }^{63}$ Reference is made to the international workshops "Human longevity, individual life duration and growth of oldest-old population”, International Union Scientific Study of Population (IUSSP), Montpellier, October 2000 (see Robine et al., 2006) and "Health, ageing and work. Strategies for the new welfare society in the larger Europe", 2nd Geneva Association Health and Ageing Conference, Trieste, October 2004. The recorded and officially confirmed longest life span is that of J. L. Calment, who died at the age of 122 (Wilmoth and Robine, 2003).

${ }^{64}$ See Dugan et al. (2005); Maccheroni (1998);

65 Johnson and Kotz (1970).

${ }^{66}$ In details: Norway, Holland, Belgium, Spain, France, Finland, Italy, Great Britain, Sweden, Austria, Canada, USA, Australia, Japan, New Zealand.
} 
Table C1 Limit life table: survivors from 100,000 live births

\begin{tabular}{lccccc}
\hline Age $_{x}$ & $\ell_{x}$ & Age $_{x}$ & $\ell_{x}$ & Age $_{x}$ & $\ell_{x}$ \\
\hline 0 & 100,000 & 40 & 99,831 & 85 & 98,985 \\
1 & 99,997 & 45 & 99,799 & 90 & 98,242 \\
5 & 99,992 & 50 & 99,768 & 95 & 95,017 \\
10 & 99,983 & 55 & 99,735 & 100 & 85,236 \\
15 & 99,968 & 60 & 99,695 & 105 & 67,726 \\
20 & 99,948 & 65 & 99,642 & 110 & 42,180 \\
25 & 99,923 & 70 & 99,566 & 115 & 15,306 \\
30 & 99,894 & 75 & 99,454 & 120 & 1,980 \\
35 & 99,863 & 80 & 99,280 & 125 & 40 \\
\hline
\end{tabular}

The limit probabilities of dying $q_{\text {lim }}(x)(x=0,1, \ldots$,$) is obtained as the suitably smoothed$ sum of (the discrete version of) the original components $q_{\text {end }}(x)$ and $q_{\text {eso }}(x)$. The abridged limit survival function is shown in Table $\mathrm{C} 1$.

Forecasts are then obtained as follows:

1. By establishing a time frame for the scenario provided by $q_{l i m}(x)$ in relation to the recorded Italian mortality trends. A procedure based on the logit model ${ }^{67}$ is used: the limit survival function $\ell_{\text {lim }}(x)$ obtained from $q_{\text {lim }}(x)$ is taken as standard and, using the reconstructed and observed survival functions ${ }^{68} \ell_{x, t}(t=1945,1946, \ldots, 1998)$, the historical series of parameters $a_{t}$ and $b_{t}$ of the following relationship are estimated by ordinary least squares:

$$
Y_{x, t}=a_{t}+b_{t} Y_{x}^{l i m}
$$

where $Y_{x}^{\text {lim }}$ is the logit of the limit life table and $Y_{x, t}$ is the logit obtained from the observed $\ell_{x, t}$. Linear trend extrapolations are performed on the historical series of $a_{t}$ and $b_{t}$ in order to obtain new time sequences for parameters $a_{t}^{*}$ and $b_{t}{ }^{*}$ (to establish if and when $a_{t}{ }^{*} \rightarrow 0$ and $b_{t}{ }^{*} \rightarrow 1$ when $t$ diverges). In our case, these results are obtained when $t=2143$ for females and when $t=2170$ for males. On the basis of (C.2), it is then possible to obtain the sequence of projected life tables that reflect the characteristics of the limit situation in the period of time that stretches from 1999 to the two previously defined extremities of time.

2. By linking the mortality models obtained as explained above with the ongoing process of evolution of mortality. The gap between current and limit mortality is bridged by assuming a type of evolution that reflects the theory of expansion of mortality. ${ }^{69}$ This step is carried out in two phases. In the first one, we define the evolution of mortality resulting from the most recent trends. In the age groups where the mortality trend is decreasing, the evolution of mortality is obtained by extrapolating the recent observed historical series of $q_{x, t}$ with a conventional exponential model. ${ }^{70}$ In the groups where mortality is growingthat is, between age 25 and 35, the so-called "accident hump"- - logistic model has been

\footnotetext{
${ }^{67}$ See Brass (1971).

${ }^{68}$ Maccheroni and Locatelli (1999).

${ }^{69}$ Myers and Manton (1984)

${ }^{70}$ See Pollard (1987); Booth and Tickle (2008)
} 
fit and extrapolated. We empirically found that extrapolating these trends after year 2050 would generate an anomalous age pattern of mortality; moreover, this pattern would be incompatible with the postulated evolution of mortality towards the limit scenario. Consequently, for these ages we envisage a stationary mortality situation starting from around year 2050. In the second phase, we synthesise the projections for each year by averaging the results of the two mortality models (the logit C.2 and the exponential model). The average assigns gradually increasing linear weights to the life tables projected obtained from the logit (C.2) and decreasing linear weights to those obtained with the exponential model. The resulting projected life tables, therefore, initially take into account recent mortality trends and gradually assume the characteristics of the limit life table.

\section{About the Authors}

Michele Belloni is a post-doctoral researcher at the University Ca' Foscari of Venice. He is a fellow of the Network for Studies on Pensions, Aging and Retirement (NETSPAR), Tilburg University. He teaches Economics of Savings and Pensions at the University of Turin. Since 2001, he has been a researcher at the Center for Research on Pensions and Welfare Policies (CeRP), Collegio Carlo Alberto. His research interests include ageing, pension systems and demography.

Carlo Maccheroni is professor of demography at the Department of Statistics and Mathematics University of Turin. He is a fellow of the Carlo F. Dondena Center for Research on Social Dynamics at the University of Milan "Luigi Bocconi". He taught demography at the Institut d'Etudes Politiques in Paris. His research interests comprise methods for demographic projections, ageing and mortality. 